Chemische Mittheilungen in Betreff der China-Alkaloide und der Stickstoffbestimmung mittelst Natronkalks.

\author{
Von \\ E. A. van der Burg. *) \\ Lector der Chemie.
}

In der ersten Nummer des Tijdschrift voor Wetenschappelijke Pharmacie, Jahrgang 1865 veröffentlichte ich eine Mittheilung über das präformirte Vorkommen des Chinidins in manchen Chinarinden. Am Schlusse dieser Mittheilung gab ich meine Absicht zu erkennen die quantitative Bestimmung und namentlich die Trennung der Chinaalkaloide näher zu behandeln.

Seit der Zeit habe ich mich mit dieser Untersuchung stets eifrig beschäftigt, wobei sich meine Aufmerksamkeit hauptsächlich auf die von de Vrij und die von Rabourdin befolgten Methoden richtete; ferner auf das. Verhalten der Chinaalkoloide zu Glaubersalz- und Seignettesalzlösungen, das C. Mann in St. Petersburg, und zu einer Lösung von Kaliumplatincyanür, das Delffs vorläufig studirt hat.

Zur Prüfung von de Vrij's Methode fand ich mich veranlasst 1. dadurch, dass diese, so weit diess möglich, eine quantitative Bestimmung der verschiedenen in der Chinarinde vorkommenden Basen bezweckt, und 2. durch den Umstand, dass bei der Anwendung dieser Methode auf eine Stammrinde von Cinch. Calisaya aus Java hinsichtlich der Gesammtmenge der Alkaloide von mir ungefähr dasselbe Resultat erhalten wurde, als das, welches von de Vrij angegeben worden war; bei der Trennung der in dieser Rinde anwesenden Basen waren meine Resultate von den seinigen jedoch ganz abweichend und ergaben sich mir gewichtige Anstände, die mich die vollständige Unzulänglichkeit der Methode fürchten liessen. So ward z. B. nach der Behandlung mit Aether zum Entfernen des Chiniıs, durch eine concentrirte Lösung von Jodkalium kein sandig krystaliinischer, sondern ein harziger Niederschlag erhalten. Ich meldete de

*) Aus dem Holländischen übertragen von der Redaction. 
Vrij diess weniger übereinstimmende Resultat, was zur Folge hatte, dass er seine Methode abänderte ${ }^{*}$ ). Doch auch bei genauer Befolgung der vorgeschlagenen Abänderung war der Erfolg nicht befriedigend und ich beschloss die Methode einer sorgfältigen Untersuchung zu unterwerfen.

Rabourdin's zur Bestimmung (n ich t zur Trennung) der Chinaalkaloide bestimmte Methode hatte mir früher wie ich glaubte gute Resultate geliefert. Die näher anzugebenden Versuche hatten zum Zwecke mir völlige Gewissheit in dieser Hinsicht zu geben.

Das Studium des Verhaltens der Ghinabasen zu den genannten Salzen geschah in der Absicht vielleicht auf diesem Wege eine zweckentsprechende Methode zur Trennung dieser Alkaloide $\mathfrak{z u}$ finden.

Die Analyse der Hydrocyanplatinverbindungen der Chinabasen hat mich schliesslich zur Prüfung der Stickstoffbestimmung nach der bekannten Methode von Varrentrapp und Will geführt:

Ieh stellte mir also die Aufgabe nach einander zu"prüfen:

1. die Methode von de Vrij zur Bestimmung der Menge der Alkaloide in Chinarinden;

2. die Methode Rabourdin's;

3. das Verhalten der Chinabasen zu Seignette- und Glaubersalz;

4. das Verhalten der Chinaalkaloide zu Kaliumplatincyanür, und

5. die Stickstoffbestimmung nach Varrentrapp und Will.

\section{Die Methode de Vrij's.}

In der Hauptsache besteht de Vrij's in dem Tijdschrift voor Wetenschappelijke Pharmacie, 1864 pag 292 mitgetheiltes, und an der oben schon angeführten Stelle abgeändertes Verfahren in Folgendem: Trocknen des Rindenpulvers im Wasserbade, Mischen mit einem Viertel seines Gewichtes Kalkhydrat, fünf Minuten langes Kochen dieses Gemenges mit seinem zehnfachen Gewichte Spiritus von 0,852 spec. Gewicht, kochendes Filtriren, Auswaschen mit einer gleichen Menge kochenden Spiritus; Uebersättigen des alkoholischen Filtrats mit verdünnter Essigsäure, Verdampfen, Lösen des Rückstandes in Wasser, Filtriren, Eindampfen der wässerigen Lösung der Alkaloide auf ein geringes Volumen, Vermischen mit einem kleinen Ueber-

*) Siehe Tijdschrift voor Wetenschappelijke Pharmacie, IV. Serie, I. Jahrg. 1865, No. 1 . 
schuss von starker Kalkmilch, Filtriren, Auswaschen, Trocknen und Auskochen des dadurch erhaltenen Niederschlags mit Alkohol von 0,819 spec. Gew. Nach dem Filtriren der alkoholischen Flüssigkeit, dem Verdampfen und Trocknen wird der Rückstand als das Gewicht sämmtlicher in der Rinde vorhandener Alkaloide in Rechnung gebracht.

Um die verschiedenen darin enthaltenen Chinaalkaloide so genau wie möglich quantitativ zu bestimmen, werden die sämmtlichen Alkaloide in verdünnter Essigsäure gelöst, nöthigenfalls filtrirt, und das Filtrat in einem Scheidetrichter mit einem kleinen Ueberschusse kaustischen Natrons und einer $\mathbf{1 5}$ mal das Gewicht sämmtlicher Alkaloide betragenden Menge Aethers geschüttelt, die Mischung darauf mindestens sechs Stunden ruhig stehen gelassen; die ätherische Lösung abgeschieden, verdampft, der Rüekstand getrocknet, gewogen und als mit geringen Spuren anderer Alkaloide verunreinigtes Chinin in Rechnung gebracht.

Der in Aether unlösliche Theil wird jetzt in verdünnter Essigsäure gelöst und diese Lösung, nöthigenfalls nach dem Filtriren, fast zur Trockne verdampit.

Der in der möglichst kleinen Menge Alkohol gelöste Rückstand wird mit einer concentrirten Jodkaliumlösung vermischt, mit einem Stäbchen umgerührt, das abgeschiedene jodwasserstoffsaure Chinidin gesammelt, bei $100^{\circ}$ getrocknet, gewogen und für je 100 Theile dieser Verbindung 71,68 Theile Chinidin in Rechnung gebracht, nach der Formel $\mathrm{C}_{40} \mathrm{H}_{24} \mathrm{~N}_{2} \mathrm{O}_{4}, \mathrm{HJ}$.

Die von dem jodwasserstoffsauren Chinidin durch ein Filter abgeschiedene Flüssigkeit würde nın durch kaustisches Natron gefällt und das Präcipitat als Cinchonin oder als ein Gemenge von Cinchonin und Cinchonidin in Rechnung gebracht werden müssen; doch es versteht sich wohl von selbst, dass es $d e V_{r i j}$ 's Absicht sein muss auch in dieser Hinsicht sein Verfahren abzuändern; denn man hat es ja nach dem Sammeln des jodwasserstoffsauren Chinidins mit einer alkoholischen Lösung zu thun, aus der also durch kaustisches Natron keine Fällung noch gelöster Alkaloide stat:findet. Desshalb wurde das alkoholische Filtrat durch Abdampfen von Alkohol befreit, der Rückstand in essigsäurehaltigem Wasser gelöst und dann erst durch kanstisches Natron gefällt.

Die erste Schwierigkeit, der ich bei dem Befolgen des abgeänderten Verfahrens begegnete, war die Behandlung sämmtlicher Alkaloide mit Aether in einem Scheidetrichter. Vollständige Abschei- 
dung der ätherischen Lösung war unmöglich; denn ausser der untersten wässerigen und der obersten ätherischen Lösung war ja ein weisses Präcipitat vorhanden, welches diese Scheidung verhinderte. Bei jedem Versuche diesen Niederchlag abzusondern ward anch eine nicht unbedeutende Menge des Aethers entfernt. Unvollkommne Abscheidung dieses Aethers durch Abgiessen und Auswaschen des Rückstandes mit einer neuen Menge dieses Lösungsmittels musste nothwendig zu ungenauen Resultaten führen, da alsdann von der vorgeschriebenen Menge abgewichen wurde, und man dem zu Folge das wieder in Lösung Kommen des Chinidins und Cinchonidins (falls anch diese Base vorkommen sollte) zu fürchten hatte, die sich durch das ruhige Stehen. in Krystallen abgeschieden hatten.

Eine andere Schwierigkeit bestand in der Löslichkeit der verschiedenen Chinabasen im Aether selbst. Diese Löslichkeit ist namentlich für Chinin und Chinidin unter 'denselben Bedingungen bei Weitem nicht so verschieden, dass sie eine Methode zur Trennung dieser Basen, auch nicht annäherungsweise, zulässt.

Um die Löslichkeit bei Anwendung eines Aethers von 0,72 spec. Gew. (bei $18^{\circ}$ C.) kennen zu lernen, ward sie nach der weiter unten beschriebenen Methode mit folgendem Resultate bestimmt:

1 Theil bei $100^{\circ}$ getrocknetes Chinin erfordert bei $22^{\circ} \mathrm{C}$. etwa $23,0 \mathrm{Th} .{ }^{*}$ )

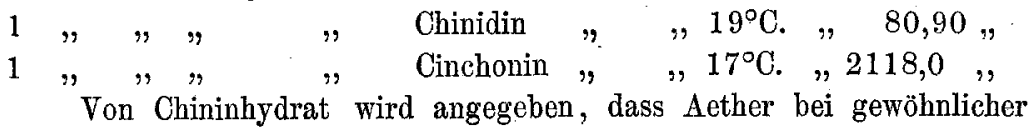

*) Die angegebene Zahl ist das Mittel aus 4 Bestimmungen. Genau konnte diese Löslichkeit des Chinins nicht bestimmt werden; in seiner Verhalten zu Aether unterscheidet es sich von den beiden anderen Chinaalkaloiden durch •die Fähigkeit der gesättigten ätherischen Lösung gefälltes und getrocknetes, also amorphes Chinin in einea gallerteartigen Zustand übergehen zu lassen. Die Neigung des Chinins unter diesen Umständen zu gelatiniren ist so gross, dass eine gesättigte Lösung oft schon bei einem geringen Sinken der Temperatur in eine helle durchscheinende Gallerte übergeführt wird. Ist die Gallerte einmal gebildet, und sucht man sie durch Schütteln mit einer neuen Menge Aethers aufzulösen, so geschieht diess ziemlich träge und erst nach dem Verwenden einer beträchtlichen Quantität.

Betrachtet man sie unter dem Mikroskop, so zeigt sie sich als eine durchscheinende, aufgeschwollene Masse, in welcher dunkle Kerne amorphen Chinins vorkommen, und lässt man sie an der Luft liegen, so bleibt bald nichts anders übrig, als das Chinin in dem gewöhnlichen pulverförmigen Zustande. 
Temperatur $1 / 60$ seines Gewichtes löse ${ }^{*}$ ), was also mit meinem Versuche nicht übereinstimmt.

Van Heijningen gibt an ${ }^{* *}$ ), dass das Chinidin sich bei $8^{\circ} \mathrm{C}$. in 90 Theilen Aether löse, diese Angabe weicht also auch von meinem Resultate ab.

Mit Rücksicht auf die Verwendung des Aethers zur Trennung der Chinabasen mussten ausserdem die beiden folgenden Fragen beantwortet werden :

1. Ist die Löslichkeit der Alkaloide im frisch gefällten Zustande dieselbe? und

2. Wird sie modificirt, wenn es sich um ein Gemenge von frisch gefällten Basen handelt?

Die erste Frage kann hinsichtlich des Chinidins und Cinchonins mit Sicherheit bejahend beantwortet werden. Von jedem von beiden warden für sich bestimmte Mengen abgewogen, in verdünnter Essigsäure gelöst und durch Aetznatron gefällt, hierauf folgte sofort das Schütteln mit Aether, der anfangs in unzureichender Menge verwandt wurde, während nachher jedesmal nach gutem Schütteln und nach Verlauf einiger Zeit so oft 5 CC. Aether weiter zagesetzt wurden, bis die beiden Schichten helle geworden waren und die Lösung stattgefunden hatte. Es war freilich unter diesen Umständen etwas weniger Aether erforderlich, doch fand diess leicht in dem. Umstande seine Erklärung, dass in der mit Aether gesättigten, wässerigen Flüssigkeit auch etwas von den Alkaloiden gelöst bleibt; so waren z. B. bei $18^{\circ} \mathrm{C}$. für 0,016 Grm. bei $100^{\circ}$ getrockneten Cinchonins $46 \mathrm{CC}$. $=33 \mathrm{Grm}$. nöthig; die Löslichkeit verhielt sich also wie 1:2062.

Von Chinidin wurden auf diese Weise für 1 Theil bei derselben Temperatur 74,5 Theile erfordert. Grösser war die Differenz bei reinem Chinin und seine Löslichkeit unter den gegebenen Verhältnissen schwer mit Genauigkeit zu bestimmen. Denn als 0,24 Grm. gelöst und gefällt warden, waren $4 \mathrm{CC}=3 \mathrm{Grm}$, des Aethers schon zureichend um bei $18^{\circ} \mathrm{G}$. den Niederschlag verschwinden zu machen; so dass also hier 1 Theil in 12,5 Theilen Aether gelöst worden war $\left.^{* * *}\right)$.

*) Handwörterbuch der reinen und angewandten Chemie, Il. Band, S. 159 und Scheikundige Onderzoekingen, door G. J. Mulder, Th. V. p. 250.

**) Scheikundige Onderzoekingen, door G. J. Mulder, Th. V. p. 250.

***) Dass diese Angabe von der Wahrheit nicht weit entfernt sein kann, 
Bezüglich der zweiten Frage muss bemerkt werden, dass die Löslichkeit eines Gemenges der Chinabasen wieder eine ganz andere ist:

0,010 Grm. bei $100^{\circ}$ getrockneten Cinchonins, $0,201 \quad " \quad " \quad, \quad$ Chinidins, $0,200 \quad " \quad, \quad, \quad, \quad$ Chinins

erforderten bei $18^{\circ} \mathrm{C} .80 \mathrm{CC}=57,6$ Grm. statt ungefähr 21 Grm.,

ward durch die folgenden Versuche bestätigt. Vorher muss ich jedoch daran erinnern, dass vor einigen Jahren von Roger (J. Pharm. XLI, 204) bemerkt wurde, dass, wenn man beim Untersuchen von schwefelsaurem Chinin nach der Liebig'schen Methode reinen (von Alkohol befreiten) Aether anwendet, ein Theil des Chinins ungelöst bleibt, und die Lösung nach Verlaut einiger Zeit zu einer durchscheinenden Gallerte gesteht. Zur vollkommenen Lösung des Chinins aus einem Gramm des schwefelsauren Salzes sind nacil. Roger 25 Grm. absoluten Aethers nöthig.

Der Versuch Liebigs ward von mir in den Verhältnissen wiederholt wie sie in Gerhardt's Traité de Chimie Organique T. IV, p. 118 angegeben sind, indem ich $1 \mathrm{Grm}$. reinen schwefelsauren Chinins mit $16,6 \mathrm{CC}$. Aether (von 0,72 spec. Gew. bei $18^{\circ}$ ) und 1,5 CC. Ammon übergoss und schüttelte. Es entstanden darauf 2 vollkommen helle Flüssigkeiten, doch als die Menge des Aethers bis auf $8 \mathrm{CC}$. reducirt wurde, war bald das Ganze zu einer durchscheinenden Gallerte gestanden. Bei Verwendung von 10,12 and $13 \mathrm{CO}$. Aether entstand die Gallerte gleichfalls, aber in geringerer Menge, doch als man 14 CC. verwandte, konnte nichts mehr davon wahrgenommen werden. Die Temperatur blieb bei diesen verschiedenen Versuchen dieselbe und zwar $21^{\circ} \mathrm{C}$. Es ist also klar, dass die ganze Erscheinung, welche schon früher beobachtet, aber stets in einen geheimnissvollen Schleier gehüllt war (der Eine spricht von "noch nicht ermittelten Bedingungen ;" ein Anderer von "versehiedenen Modificationen des Chinins" u. s. w. willkührlich hervorgerufen werden kann und ganz vor der Menge des angewandten Aethers abhängig ist. Ist diese nicht zureichend, so wird der Ueberschuss des ungelösten Chinins zur Gallerte. Da nun 14 CO. $=10 \mathrm{Grm}$. sind, und in $1 \mathrm{Grm}$. schwefelsaurem Chinin $0,743 \mathrm{Grm}$. Chinin enthalten ist, so würde also ans dem Vorausgehenden folgen, dass im. frisch gefällten Zustande 1 Theil Chinin bei $21^{\circ} \mathrm{C}$. ungefähr 13 Theile des genannten Aethers erfordert.

Dieselben Versuche wurden mit Aether gemacht, den man mit Wasser geschüttelt und 24 Stunden lang damit in Berührung gelassen hatte, doch ohne dasss ein Unterschied bemerkt werden konnte. Als jedoch käuflicher Aether (von 0,73 spec. Gew. bei $22^{\circ}$ C.) genommen ward, waren die Flüssigkeiten, selbst bei Verwendung von nur $8 \mathrm{CC}$. vollkommen hell geblieben. Vermuthlich wird also Alkoholgehalt hier der Grund des Nicht-Gelatinirens sein, was durch das Ver- 
welche nöthig gewesen sein würden, wenn die für Cinchonin erforderliche Menge Aethers auch für das Chinin und Chinidin ausreichend wäre. Dass also für den bewussten Zweck vom Aether wenig Heil $z u$ erwarten ist, wird man mir auf Grund des Obenstehenden gern zugestehen.

Um die Zweckmässigkeit der Bestimmung und Trenning des Chinidins als jodwasserstoffsaures Chinidin zu beurtheilen, bestimmte ich zuerst das Verbalten auch der Chinin- und Cinchoninsalze zu Jodwasserstoffsäure und Jodmetallen, wobei sich mir ergab, dass das saure jodwasserstoffsaure Chinin nach Regnault's *) Formel:

$$
\mathrm{C}_{40} \quad \mathrm{H}_{24} \mathrm{~N}_{2} \mathrm{O}_{4}, 2 \mathrm{HJ}+5 \mathrm{HO}
$$

zusammengesetzt ist.

mischen von reinem Aether mit 2 Proc. Alkohol bestätigt ward, wodurch auch bei Verwendung von $8 \mathrm{CC}$. keine Gallerte entstand. Wohin Oberflächlichkeit **) in der Beobachtung führt, hat sich wieder deutlich bei Kerner (diese Zeitschrift Jahrgang 1., S. 150) gezeigt. Nur daraufhin, dass die in einer schwefelsaures Ammon enthaltenden Flüssigkeit gebildete Gallerte Schwefelsäure und gebundenes Ammon enthält, wird vermuthet, dass als Bedingung des Gelatinirens die Bildung einer in Aether unlöslichen Doppelverbindung des Chininsalzes mit dem entstehenden Ammoniaksalze anzusehen ist. Nichts wäre einfacher gewesen um die Ungereimtheit dieser Hypothese zu beweisen, als den Versuch mit reinem Chinin und Aether zu machen wie oben angegeben ist.

Wie auseinander gehend die Angaben sind in Betreff der Löslichkeit des Chinins namentlich in Wasser von gewöhnlicher Temperatur, kann aus Folgendem ersehen werden: die Verfasser des Handwörterbuchs (II. Band p. 159) geben an, dass Chininhydrat ungefăhr 400 Theile kalten und 250 Theile siedenden Wassers zur Lösung bedarf; van Heijning en (Scheik. Onderzoekingen Th. V. p. 250) sagt: „Bei $10^{\circ}$ C. löst sich e in Theil in 830 Theilen Wassers anf und bei der Siedebitze erfordert ein Theil 200 Theile Wasser." Gerhardt (Traité de Chimie organique T. IV. p. 109) spricht wieder von 350 Theilen kalten und 400 Theilen (!) siedenden Wassers. Was der Grund dieser grossen Differenzen ist, weiss ich nicht; die Löslichkeit in Wasser ist von mir nicht bestimmat worden; doch halte ich die Bemerkung nicht für überflüssig, dass man zur Darstellung von Chinin bei dem Fällen sehr vorsichtig zu Werke gehen muss um die Bildung eines basischen, sehr schwer löslichen Salzes zu vermeiden.

*) Gerhardt, Traité de Chimie organique T. IV pag. 114.

**) Wenn ein gewissenhaiter Forscher sich in einer Beobachtung irrt oder etwas für wahrscheinlich hält, ohne dazu vollkommen berechtigt za sein, so ist eine Widerlegung dankenswerth. Nicht zu billigen aber ist es, wenn sie in beleidigendem Ausdruck gegeben wird, durch welcher in keiner Weise etwas gewonnen werden kann. Die Redaction. 
Ein neutrales krystallisirtes jodwasserstoffsaures Chinin von gleicher Zusammensetzung wie jodwasserstoffsaures Chinidin konnte nicht erhalten werden. Setzt man einer wässerigen Lösung von schwefelsaurem Chinin Jodkaliumlösung zo, so opalisirt die Flüssigkeit nur; hat man aber das löslichere salzsaure Chinin auf dieselbe Weise behandelt, so erhält man eine weisse, milchige, trübe Flüssigkeit, aus der sich bald ein harziger durchscheinender Niederschlag absetzt, der auf keine Weise in Krystalle übergeführt werden kann. War das schwefelsaure Chinin in schwefelsäurehaltigem Wasser und das salzsaure Chinin in salzsäurehaltigem Wasser gelöst, so liess Jodkalium aus dem sauren Salze nach Verlauf einiger Zeit orangeroth gefärbte Krystallnädelchen entstehen, welche sich unter dem Mikroskope als prächtige Federn zeigten. Anfänglich. entstand kein Niederschlag; die Flüssigkeit ward nur hellgelb gefärbt. Das saure jodwasserstoffsaure Chinin löste bei erhöhter Temperatur Chinin auf; beim Erkalten schied sich eine harzige Masse ab.

Behandelte man schwefelsaures Cinchonin bei gewöhnlicher Temperatur mit Wasser, filtrirte and setzte der wässerigen Lösung Jodkalium zu, so ward die Flüssigkeit anfangs weiss, trübe; nach kurzer Zeit hatte sich ein reichliches, farbloses, krystallinisches Präcipitat abgeschieden, welches unter dem Mikroskop die Gestalt von Trapezen zeigte, die oft sternförmig gruppirt waren. Ebenso verhielt sich das salzsaure Cinchonin; doch war wegen seiner grossen Löslichkeit in Wasser die Menge des Niederschlags beträchtlicher.

Dieses Verhalten ist wichtig, weil sich in dieser Hinsicht Uebereinstimmung zwischen Chinidin and Cinchonin findet. Bei Vermischung einer wässerigen Lösung ron schwefelsaurem Chinidin mit Jodkalium erhält man freilich fast unmittelbar einen krystallinischen Niederschlag, was bei Cinchonin nicht so direct stattfindet, doch nach Verlauf einiger Zeit ist dieser Unterschied nicht mehr vorhanden. Man wird also umsichtig dabei zu Werke gehen müssen, wenn man die Reinheit von schwefelsaurem Chinin untersicht und darin schwefelsaures Chinidin nach de Vrij durch Schütteln mit kaltem Wasser, Zusatz einiger Tropfen einer Lösung von Jodkalium und Umrühren mit einem Glasstabe aufsucht, wodurch bei Anwesenheit ron Chinidin alsbald Streifen auf dem Glase und ein krystallinischer Niederschlag entstehen werden *).

- Wenn nun kein schwefelsaures Chinidin, aber wohl schwefelsaures

*) Tijdschrift voor Wetensch. Pharm. II. Serie, 4. Jahrg. p. 67. 
Cinchonin vorhanden wäre, würde man also leicht irren und ein falsches Urtheil fällen können.

Zur Analyse des auf dem angegebenen Wege gebildeten jodwasserstoffsauren Cinchonins wurden $0,4 \mathrm{Grm}$. angewandt, welche in warmem Wasser gelöst and mit jod- und chlorfreier Sodalösung zersetzt wurden. Man filtrirte, übersättigte das Filtrat mit verdünnter Salpetersäure und setzte salpetersaures Silberoxyd zu. Erhalten wurden 0,27 Grm. Cinchonin $=67,5$ Proc. and 0,21 Grm. Jodsilber $=0,114 \mathrm{HJ}=28,5$ Proc. Es handelte sich also auch hier um ein neutrales Salz von der Zusammensetzung $\mathrm{C}_{40} \quad \mathrm{H}_{24} \quad \mathrm{~N}_{2} \mathrm{O}_{2} \quad \mathrm{HJ}{ }^{*}$ ), denn es wurden

berechnet: erhalten :

Cinchonin 70,64 Proc. . . 67,5 Proc.

Jodwasserstoff 29,35 Proc. . . 28,5 "

Ward den Lösungen von schwefelsaurem and salzsaurem Cinchonin in Wasser, welches die entsprechenden Säuren enthielt, Jodkalium zugesetzt, so entstand auch hier eine schwach gelbe Färbung und es schied sich, nicht sofort, sondern nach Verlauf einiger Zeit, ein geringes, krystallinisches Sediment ab. Durch Jodkalium entstand in den wässerigen Lösungen von schwefelsaurem und salzsaurem Chinidin sofort ein weisser Niederschlag, der jedoch als solcher unter dem Mikroskope keine deutliche Krystallform zeigte, sondern erst, wenn er in siedendem Wasser gelöst und langsam abgekühlt ward. In den sauren Lösungen hatten sich nach Verlauf einiger Zeit mikroskopische, bündelförmig vereinigte, gelb oder hellroth gefärbte Krystalle von dem sauren Salze abgeschieden.

Es war also noch die Frage, ob es auch ein neutrales jodwasserstoffsaures Chinin gebe und diese Verbindung durch die oben erwähnten harzigen Niederscbläge vertreten werde. Desshalb wurden diese ausgewaschen, in Alkohol gelöst, filtrirt und auf einem Wasserbade verdampft bis keine Gewichtsdifferenz mehr wahrgenommen wurde.

0,6 Grm. lieferten 0,395 Grm. Chinin $=65,84$ Proc.

und $0,268 \mathrm{AgJ}=0,146 \mathrm{Grm}$. HJ $=\frac{24,33 \quad,}{90,17 \text { Proc. }}$

Verlust $=9,83 \quad$,

Die Formel $\mathrm{C}_{40} \mathrm{H}_{24} \mathrm{~N}_{2} \mathrm{O}_{4}, \mathrm{H} \mathrm{J}$ ergibt bei der Berechnung:

*) Der Wassergehalt wurde nicht bestimmt. Nach Regnault enthält diess Salz 2 Aeq. Krystallwasser. 


$$
\begin{aligned}
& \text { 71,68 Proc. Chinin und } \\
& \frac{28,32, \% \text { Jodwasserstoff }}{100,00 \text { Proc. }}
\end{aligned}
$$

Die grossen und äbereinstimmenden Unterschiede wurden nicht durch die Analyse verursacht, sondern waren vermuthlich in einem Gehalt an Wasser zu suchen, das bei der Temperatur von $100^{\circ}$ nicht verjagt wurde.

Darum wurde der durch Neutralisation des sauren jodwasserstoffsauren Chinins mit Chinin erhaltene harzige Niederschlag mehrere Stunden lang auf einem Wasserbade erhitzt, und dann die Temperatur in einem Luftbade noch gesteigert.

0,79 Grm. bei $120^{\circ}$ erhitzt liessen Rückstand 0,745 Grm.

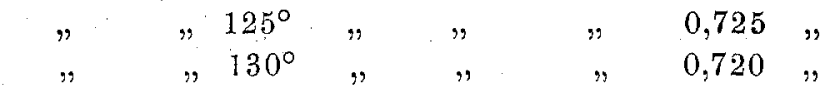

Im Ganzen hatten sie also verloren 0,07 Grm. $=8,86$ Proc. $0,305 \mathrm{Grm}$ : bei $100^{\circ}$ getrocknet, gaben 0,191 Chinin $=62,62$ Proc. $0,205 \mathrm{Grm}$. bei $100^{\circ}$ getrocknet, lieferten 0,095 Grm. AgJ $=0,0517$ Grm. $\mathrm{HJ}=25,22$ Proc.

Also erhalten:

$$
\begin{array}{rll}
8,86 & \text { Proc. } & \text { Wasser } \\
62,62 \quad " & \text { Chinin } \\
25,22 \quad " & \text { Jodwasserstoff } \\
\hline 96,70 & \text { Proc. } &
\end{array}
$$

Die Formel $\mathrm{C}_{40} \mathrm{H}_{24} \mathrm{~N}_{2} \mathrm{O}_{4}, \mathrm{HJ}+5 \mathrm{HO}$ erfordert:

$$
\begin{array}{rrl}
9,05 & \text { Proc. } & \text { Wasser } \\
65,19 \% & \text { Chinin } \\
25,75 \quad \% & \text { Jodwasserstoff } \\
\hline 99,99 & \text { Proc. } &
\end{array}
$$

Der harzige Niederschlag ist also als ein Hydrat von neutralem jodwasserstoffsaurem Chinin anzusehen.

Gerhardt*) beschreibt das neutrale Salz folgendermaassen: „Man erhält es, indem man Jodwasserstoffsäure mit Chinin sättigt, und die Lösung bei gelinder Wärme verdampft. Es ist in kaltem Wasser sehr wenig löslich, löslicher in siedendem Wasser, welches es beim Erkalten in aus dünnen Nadeln zusammengesetzten Gruppen absetzt; es ist sehr löslich in Alkohol. Ein Ueberschuss von Jodwasserstoffsäure verwandelt es in ein saures Salz."

*) Traité de Chimie organique T. IV. p. 114. 
Eine die Zusammensetzung ausdrückende Formel wird nicht angegeben.

Ich versuchte es auf diesem Wege ein krystallisirtes neutrales Salz darzustellen, aber sobald die Nentralisation der Säure vollkommen erreicht war, schied sich der harzige Niederschlag ab, welcher sich weder durch Wasser, noch durch Alkohol in Krystalle umwandeln liess.

Als jedoch das Fluidum beim Erkalten der hellen wässerigen Flüssigkeit noch sauer reagirte, wurden sofort sehr schöne, hellgelb gefärbte, dünne glänzende Nadeln abgesetzt, die vielleicht ohne Analyse für die neutrale Verbindung angesehen worden sind, obschon sie nach den folgenden Resultaten nichts anders darstellen als die saure Jodwasserstoffverbindung. 0,382 Grm. auf dem Wasserbade erhitzt verloren 0,031 Grm. Wasser $=8,115$ Proc.; bei weiterer Erwärmnng unter und bis zu $115^{\circ}$ ward nichts mehr verjagt, bei $135^{\circ}$ nur eine Spur. $0,5 \mathrm{Grm}$. (lufttrocken) gaben $0,245 \mathrm{Grm}$. Chinin $=49$ Proc. und 0,37 Grm. Jodsilber $=0,2016$ Grm. HJ $=40,32$ Proc.

Gefunden :

Wasser . . . 8,115

Jodwasserstoffsäure . $\quad 40,320$

Chinin . . . 49,000
Berechnet:

7,20 Proc.

$40,96 \quad$ "

51,84,

Es bleibt somit kein Zweifel darüber, dass die Zusammensetzung dieser Krystalle $\mathrm{C}_{40} \mathrm{H}_{24} \cdot \mathrm{N}_{2} \mathrm{O}_{4}, 2 \mathrm{HJ}+5 \mathrm{HO}$ ist.

Ausser Chinidin bilden also auch Cinchonin und Chinin mit Jodwasserstoff neutrale Salze, von denen ersteres krystallinisch, letzteres amorph ist *). Alle zeichnen sich durch ihre Schwerlöslichkeit in Wasser aus und das Chinidinsalz auch noch durch Schwerlöslichkeit in Alkohol, während die Chininverbindung von diesem Lösungsmittel sehr leicht aufgenommen wird.

Hat man desshalb ein Gemenge von Chinin, Cinchonin and Chinidin in die entsprechenden neutralen Salze übergeführt und der wässerigen Lösung derselben Jodkalium zugesetzt, so fällt sofort das harzige

*) Nachdem obige Zeilen schon geschrieben waren, ersah ich, dass auch de Vrij (De kinakultuur op Java, op het einde van het jaar 1859, kort beschreven door Fr. Junghuhn en J. E. de Vrij, pag. 97) die Beobachtung gemacht hat, dass das neutrale jodwasserstoffsaure Chinin nicht krystallisirbar ist. Analyse oder Eigenschaften desselben werden jedoch nicht angegeben. 
Chininsalz nieder, das sich allmählich mit den krystallisirten Chinidinund Cinchoninverbindungen vermischt.

Hierdurch ist also deutlich geworden, warum ich (siehe oben bei unvollkommner Entfernung des Chinins einen harzigien Niederschlag erhalten musste und warum eine alkoholische Lösung der neutralen Salze angewandt werden muss um eine theilweise Trennung wenigstens des Chinins und Chinidins zu. Wege zú bringen.

In dem Besitze dieser Data konnte also die Erwartung von dem Gebrauche des Jodkaliums zur Trennung der Chinaalkaloide nicht günstig sein. Um nun weiter zu bestimmen, welcher Werth de Vrij's Methode beizulegen sei, wurden

$$
\begin{array}{lll}
0,147 & \text { Grm. } & \text { Chinin } \\
0,055 . & \text { Cinchonin und } \\
0,754 & \text { Chinidin }
\end{array}
$$

in essigsäurehaltigem Wasser gelöst und mit 25 Grm. Kleie vermischt unter Zusatz von Wasser bis ein dicker, gleichförmiger Brei entstand, der auf dem Wasserbade getrocknet und sodann mit Alkohol u. s. w. wie oben angegeben behandelt ward.

Die Alkaloide waren vorher auf dem Wasserbade getrocknet und ihre Reinheit mit der erforderlichen Genauigkeit untersucht worden.

In den angegebenen Mengen wurden die Chinabasen verwandt, weil diese mit de Vrij's Angabe über die Zusammensetzung der Stammrinde von Cinchona Calisaya von Java No. $7^{*}$ ) ungefähr übereinstimmten.

Das Resultat ist in nachstehender Tabelle angegeben:

$$
\text { Angewandt: }
$$

\begin{tabular}{lll} 
Chinin & 0,147 & Grm. \\
Cinchonin & $0,055 \quad "$ \\
Chinidin & $0,754 \quad \%$ \\
\cline { 2 - 3 } & 0,956 & Grm.
\end{tabular}

Erhalten :

$$
\begin{array}{ll}
0,085 & \text { Grm. } \\
0,183 \quad, & \\
0,548 \quad, \\
\hline 0,816 & \text { Grm. }
\end{array}
$$

Die alkoholische Lösung hatte aber 0,817 Grm. als Betrag sämmtlicher Alkaloide hinterlassen.

Aus der noch näher anzugebenden Reaction mit Kaliumplatincyanür in Verbindung mit dem Verhalten zu Jodkalium ergab sich, dass der Rückstand der (durch Schütteln in einem mit Korkstopfen verschlossenen Fläschchen und so weit diess möglich war Abscheiden vermittelst einer Pipette erhaltenen) ätherischen Lösung eine ziemlich beträchtliche

*) Tijdschrift vor Wetensch. Pharm. III. Serie 6. Jahrg. p. 207. 
Menge Chinidin enthielt. Die Lösung des nach der Behandlung mit Aether und Jodkalium übrig bleibenden enthielt ausser Cinchonin auch noch Chinin, Chinidin und Kalk, wie diess das Verhalten zu Chlor and Ammon, Jodkalium, Kaliumplatincyanür und oxalsaurem Ammon zeigte.

Dás Resultat konnte also weder in Betreff der erhaltenen Mengen, noc’ hinsichtlich der Reinheit der Producte günstig genannt werden.

Uebrigens körnte mit Recht bemerkt werden, dass Kleie keine Chinarinde ist und vielleicht darin der Grund des weniger günstigen Resultates $\mathrm{zu}$ suchen sei. Desshalb wurden $50 \mathrm{Grm}$. grobes Chinarindenpulver mit $4 \%$ Salzsäure enthaltendem Wasser bei gewöhnlicher Temperatur so lange ausgezogen bis die durchgelaufene Flüssigkeit mit Chlorwasser und Ammoniak keine Reaction mehr zeigte, und Natronlauge keinen Niederschlag mehr hervorbrachte. Kaliumquecksilberjodid liess noch eine schwache Trübung entstehen. Sodann wurde der Rückstand mit Wasser ausgewaschen bis die saure Reaction verschwunden war, in 2 Theile getheilt und die eine Hälfte innig vermischt mit der essigsauren Lösung derselben Menge Chinaalkaloide wie sie oben angegeben ist.

Jetzt wurden nur 0,61 Grm. Alkaloide erhalten, was einem Verlust von $36,2 \%$. gleichkommt. Es ergab sich denn auch, dass der Rest bei erneuertem Auskochen mit Alkohol noch Chinabasen abgab. Das Ausziehen der Alkaloide war also unter diesen Umständen unvollkommen gewesen.

Zum dritten Male ward der Versuch wiederholt, doch jetzt sehr feines Pulver von brauner Chinarinde angewandt. Dass das Ausziehen der Basen mit salzsäurehaltigem Wasser (in einem Deplacirungs-Apparate) nicht leicht geschieht, kann man däraus ersehen, dass, obgleich zum Ausziehen von 50 Grm. 2300 CC. gebraucht worden waren, Kaliumquecksilberjodid noch immer eine schwache Trübung hervorbrachte, wenn auch auf keinem anderen Wege ihre Gegenwart entdeckt werden konnte. Als mit Wasser ausgewaschen worden war bis durch Kaliumquecksilberjodid keine Reaction mehr wahrgenommen wurde, kam, als man wieder mit Salzsäure ausgezogen hatte, doch ein schwaches Opalisiren durch diess Reagens zum Vorscheine.

Die Hälfte der ausgezogenen Rinde ward wieder wie oben mit derselben Menge der Alkaloide vermischt und behandelt.

Das Auskochen mit der vorgeschriebenen Menge (500 Grm.) Spiritus ward 6 bis $7 \mathrm{mal}$ wiederhoit und endlich 0,86 Grm. $=90$ Proc. erhalten. Der Verlust betrug also 10 Proc. 
Nachdem der Rückstand nochmals eine Zeit lang mit $200 \mathrm{CC}$. Spiritus von derselben Dichte gekocht und die alkoholische Lösung auf gleiche Weise verarbeitet worden war, wurden noch 0,05 Grm. Alkaloide erhailten, also im Ganzen 0,91 Grm. $=95,19$ Proc.

Bei Behandlung mit Aether blieben zurück 0,239 Grm.; jetzt war der Rückstand noch einmal mit Aether behandelt worden, weil das erste Mal nur 0,085. Grm. erhalten worden waren, und auch jetzt befand sich in der Lösung neben Chinin eine grosse Menge Chinidin.

Jodkalium lieferte eine Menge Präcipitat (zu dessen Abscheidung 24 Stunden Zeit gelassen wurde), die mit $0,358 \mathrm{Grm}$. Chinidin übereinstimmte, und Aetznatron schied weiter 0,103 Grm. Niederschlag ab, der wieder Chinin, Chinidin und Kalk nebst Cinchonin enthielt. Also:

\section{Angewandt :}

Chinin . 0,147

Chinidin . . 0,754

Cinchonin . 0,055

Verlust .
Erhalten :

0,239 Grm.

0,358,

0,103,

$\frac{-}{-} \frac{0,210, "}{0,956}$

Den grossen Verlust muss man der Löslichkeit des in ziemlich beträchtlicher Menge vorhandenen Kalkhydrates in dem Waschwasser zuschreiben.

Um zu bestimmen, ob bei der Behandlung der mit Alkaloiden vermischten Chinarinde etwa durch die angewandten Agentien Umsetzung stattgefunden habe, wurden:

$$
\begin{array}{lll}
0,113 & \text { Grm. } & \text { Chinin, } \\
0,043 \quad " & \text { Cinchonin, } \\
0,580 \quad, & \text { Chinidin, }
\end{array}
$$

(alle auf dem Wasserbade getrocknet) in essigsäurehaltigem Wasser gelöst und mit $20 \mathrm{Grm}$. ausgeglühten Sandes vermengt, dann auf dem Wasserbade zur Trockne verdampft,' 5 Grm. gelöschter Kalk zugesetzt und wieder mit Alkohol u. s. w. behandelt.

Schon 150 CC. von dem Weingeiste waren ausreichend um alle Alkaloide auszuziehen, von denen erhalten wurden:

0,760 Grm., während genommen waren

$0,736 "$ so dass scheinbar

$0,024 \mathrm{Grm}$. Chinabasen mehr erhalten warden, als anfänglich verwandt worden waren.

Zum Ausziehen mit Aether von 0,73 spec. Gew. wurden gebraucht 16. CC. Diese ätherische Lösung liess zurück 0,125 Grm. 
Von jodwasserstoffsaurem Chinidin wurden abgeschieden $0,47 \mathrm{Grm}$. $=0,337 \mathrm{Grm}$. Chinidin und durch Aetznatron gefällt 0,220 Grm. Also:

\begin{tabular}{lccc} 
& Genommen: & \multicolumn{2}{c}{ Erhalten: } \\
Chinin . &. & 0,113 & 0,125 Grm. \\
Cinchonin &. & 0,043 & $0,220 "$ \\
Chinidin &. & 0,580 & $0,337 \quad "$ \\
Verlust . & - & $0,078 \quad "$
\end{tabular}

Auch hier ergab sich, dass bei dem Auswaschen des durch $\mathrm{Na}$ tronlauge hervorgebrachten Niederschlags die Flüssigkeit zuletzt eine ziemlich starke alkalische Reaction behielt, welche nicht abnahm, und zwar durch die Anwesenheit von Kalkhydrat, welches als die Ursache sowohl von dem Ueberschusse bei der Bestimmung der Gesammtmenge der Alkaloide, als von dem bei der Trennung derselben von einander erlittenen Verluste anzusehen ist.

Mit Sichcrheit dürfte also geschlossen werden, dass die angewandten Agentien zu keiner Umsetzung geführt hatten.

Sollte Jemand bemerken wollen, dass die Behandlung einer ausgezogenen und absichtlich mit.Alkaloiden vermischten Chinarinde einer natürlichen and unveränderten Chinarinde nicht gleich zu stellen ist, so würde ich ihm sofort beistimmen, aber auch gleich darauf hinweisen, dass diese Behauptung mit mehr Grund würde angeführt worden sein, falls die Resultate genau gewesen wären. Denn dann würde man noch nicht zu dem Schlusse berechtigt sein, dass diese Resultate auch bei der Anwendung auf die unveränderte Rinde würden erhalten worden sein.

Da nun aber die Umstände, unter denen gearbeitet wurde, als sehr günstig betrachtet werden dürfen, weil die Alkaloide in gelöstem Zustande der ausgezogenen und ausgewaschenen Rinde zugesetzt waren, so darf mit einem an Sicherheit grenzenden hohen Grade von Wahrscheinlichkeit vermuthet werden, dass die Resultate mit gewöhnlicher Chinarinde nicht günstiger sein werden.

Ich glaube also als Resultat meiner Untersuchung in Betreff der Methode de Vrij's die Schlüsse ziehen zu dürfen:

1) dass die vollständige Ausziehung der Alkaloide aus der Chinarinde durch Kalk and Alkohol sehr schwer geschieht;

2) dass überdiess Kalk in Lösung kommt, der später theilweise als Cinchonin in Rechnung gebracht wird, und

3) dass die Trennung der Basen auf dem angegebenen Wege unbefriedigende Resultate liefert, welche weder absoluten noch relativen 
wissenschaftlichen Werth besitzen, da sie je nach der Zusammensetzung der Chinarinde auch' relativ ganz verschieden sein werden.

\section{Das Verfahren nach Rabourdin*).}

Diese Methode ist basirt auf die Fähigkeit der kaustischen Alkalien Gerbsäure, Chinaroth, Farbstoffe und Harze aufzulösen ohne dabei auf Chinin einen Einfluss zu äussern.

Chinapulver wird bei gewöhnlicher Temperatur mit 4 Proc. ${ }^{* *}$ ) Salzsäure enthaltendem Wasser so lange extrahirt, bis die durchgelaufene Flüssigkeit nur noch schwach bitter schmeckt.

Der sauren Flüssigkeit wird ungefähr so viel Natronlauge zugesetzt, als das Gewicht der Chinarinde beträgt, der gebildete Niederschlag gesammelt, mit wenig Wasser ausgewaschen und dann gereinigt, entweder :

1) durch Lösung in verdünnter Salzsäure, die in unzureichender Menge angewandt wird, und Fällen mit Ammon, wodurch Chinin weiss und rein würde niedergesshlagen werden, oder

2) durch Zufügen eines kleinen Ueberschusses von Salzsäure, (nöthigen Falls) Filtriren, und nachheriges Zusetzen von verdünntem Ammon bis eịn brauner Niederschlag zum Vorschein kommt und nach dem Filtriren eine farblose Flüssigkeit durchläuft, aus der durch Ammon das Chinin würde abgeschieden werden, welches nur noch Spuren von Cinchonin enthalten würde, and nach dem Auswaschen an der Luft getrocknet and gewogen wird. Sollten durch einen Ueberschuss von Ammon dem braunen Niederschlage weisse Flocken beigemengt sein, so muss man zur Lösung angesäuertes Wasser zusetzen.

Von grauer China werden $40 \mathrm{Grm}$, von rother und CalisayaChina nur 10 Grm. zur Untersuchung abgeschieden. Nach dem Verfasser würde man zu einer Bestimmung kaum eine/Stunde Zeit branchen.

Im Jahre 1861 wurde diese Methode von mir geprüft and Folgendes aufgezeichnet: von 49,50 Grm. Pulver von rother China wurden 950 CC. Auszug erhalten. Der mit Wasser gekochte Rückstand der China gab zwar noch eine gefärbte Flüssigkeit, schmeckte aber

*) Journ. de Pharm. et de Chim. Juin 1861, pag. 408.

**) An einer Stelle spricht der Verfasser von 3, an einer anderen von 1 Proc. Salzsäure enthaltendem Wasser. 
nur schwach bitter. Der durch 50 Grm. Natronlauge verursachte Niederschlag war roth gefärbt. Durch das erste Zusetzen von Ammon in geringer Menge wurden die Farbstoffe grösstentheils, doch nicht vollkommen entfernt. Das durch einen Ueberschuss von Ammon abgeschiedene Präcipitat ward lange Zeit hindurch über Schwefelsäure getrocknet und wog 1,4 Grm. entsprechend 2,83 Proc. der angewandten Menge. Die von der ersten Füllung durch Natronlauge erhaltene alkalische Flüssigkeit ward auf ein kleines Volumen eingedampft und dann nach dem Erkalten filtrirt. Das auf dem Filter Zurückbleibende gab, auf dieselbe Weise wie oben behandelt, noch 0,32 Grm. Alkaloide = 0,65 Proc.; also waren $2,83+0,65$ Proc. $=3,48$ Proc. erhalten worden.

Ein zweiter Versuch ward mit 24,5 Grm. derselben China gemacht, diese aber erst eine Zeit lang mit dem salzsäurehaltigen Wasser in dem Verdrängungs-Apparate ausgezogen. Auch jetzt war eine gleiche Menge des sauren Wassers zum Ausziehen erforderlich um der letzten Flüssigkeit einen nur schwach bitteren Geschmack mitzutheilen. Die Flüssigkeit ward vor dem Fällen auf ein kleines Volumen eingeengt. Erhalten 0,96 Grm. Alkaloide $=3,92$ Proc. Bei der Schlussfällung war nicht mehr Ammon zugesetzt worden als erforderlich war um die Flüssigkeit deutlich darnach riechend zu machen. Nach Abscheidung des Niederschlags ward die schwach alkalische Flüssigkeit mit einem starken Ueberschuss von Ammon. vermischt, wodurch wieder Trübung und Ausscheidung von 0,015 Grm. Alkaloide $=0,06$ Proc. stattfand, also im Ganzen 3,92 + 0,06 Proc. $=3,98$ Proc.

Ich schloss Folgendes:

1. Das Rabourdin'sche Verfahren ist weniger kostspielig und gibt gute Resultate. Die grösste Menge Alkaloide wird erhalten, wenn die Lösung vor dem Fällen auf ein kleines Volumen gebracht und sodann mit einem grossen Ueberschuss von Ammon am Schlusse der Behandlung zerlegt wird.

2. Bei der theilweisen Fällung mit Ammon konnte keine ganz farblose Flüssigkeit erhalten werden, selbst wenn zuviel Ammon zugesetzt wurde, so dass sich mit den Farbstoffen auch ein Theil der Basen absonderte; stets zeigte sich eine hellgelbe Färbung.

3. Die fractionirte Fällung durch Ammon findet übrigens wie angegeben statt. Erst scheiden sich die Farbstoffe ab, welche sich bei einer eigens vorgenommenen Untersuchung als von Alkaloiden frei ergaben.

4. Es ist $z u$ empfehlen die Reinigung nach der zweiten angegeFresenius, Zeitschrift. IV, Jahrgang. 
benen Behandlungsweise stattfinden zu lassen. Ist nämlich ein kleiner Ueberschuss von Salzsäure angewandt, so weiss man sicher, dass alle Alkaloide in Lösung gekommen sind, und hat das Zusetzen des Ammons mehr in der Hand.

5. Die Alkaloide enthalten stets Spuren von alkclischen Erden und Farbstoffen.

6. Das Trocknen über Schwefelsäure ist im höchsten Grade wothwendig, da scheinbar vollkommen lufttrockne Chinabasen noch bedeutende und wechselnde Mengen von Wasser zurückhalten können, welches durch Schwefelsäure entfernt werden kann.

7. Zum Ausziehen muss von dem sauren Wasser mehr gebrancht werden, als vorgeschrieben ist, ja selbst eine doppelte Menge. *)

8. Die Angabe, dass in ein er Stunde die quantitative Bestimmung mit Genauigkeit geschehen könne, ist ungereimt, da das Ausziehen allein mehr Zeit erfordert.

9. Die Chinaalkaloide sind in starkem Ammon weniger löslich als in verdünntem.

10. Nicht nur das Chinin, sondern alle vorhandenen Basen werden abgeschieden, so dass die Methode nur die Gesammtmenge der Alkaloide angibt.

Seit der Zeit ward diese in dem angegebenen Sinne abgeänderte Methode von mir stets da befolgt, wo es sich um die Bestimmung der in der Chinarinde vorhandenen Menge von Basen handelte.

Um ihren Werth anf gleiche Weise zu untersuchen wie ich es hinsichtlich der von de $\mathrm{Vrij}$ befolgten Methode gethan hatte, wurden 25 Grm. grobes Pulver von mit Salzsäure ausgezogener brauner Chinarinde innig vermischt mit einer essigsauren Lösung von:

$$
\begin{array}{lll}
0,147 & \mathrm{Grm} & \text { Chinin } \\
0,055 & , & \text { Cinchonin } \\
0,754 \quad " & \text { Chinidin, }
\end{array}
$$

auf einem Wasserbade zur Trockne verdampft, sodann mit verdünnter Säure ausgezogen, indem möglichst dafür gecorgt wurde, dass keine falschen Kanäle entstehen konnten, und weiter behandelt. Die Alkaloide wurden nicht mehr über Schwefelsäure von Wasser befreit, sondern in Alkohol gelöst und die Lösung in einem Platinschälchen auf einem Wasserbade verdampft, getrocknet and gewogen.

*) Rabourdin behauptet, dass bei Anwendung von $10 \mathrm{Grm}$. Rinde 100 bis $120 \mathrm{Grm}$. Filtrat erhalten werden. 
Nur 0,665 Grm. wurden erhalten, obgleich 0,956 Grm. zugesetzt worden waren. Es ergab sich jedoch, dass das Ausziehen mit dem salzsäurehaltigen Wasser nicht hinlänglich fortgesetzt worden war, da in einem neu bereiteten Auszuge durch Chlorwasser und Ammon noch eine grüne Färbung entstand.

Mit feinem ausgezogenem Pulver ward der Versuch auf gleiche Weise wiederholt. Zum Ausziehen waren gebraucht worden $500 \mathrm{CC}$. (also in Beziehung auf das Gewicht Chinarinde die zwanzigfache Menge.)

Bei weiterem Ausziehen war die Flüssigkeit so gut wie farblos und gab mit Chlor und Ammon und mit Natronlange nur eine Spur von Reaction.

Das Ausziehen ward deshalb fortgesetzt bis wieder $500 \mathrm{CC}$. durchgelaufen waren, and diese Behandlung noch einmal wiederholt. Im Ganzen waren also jetzt $1500 \mathrm{CC}$. von dem sauren Wasser für die $25 \mathrm{Grm}$. Chinarinde verbraucht worden. Noch immer verursachte Kaliumquecksilberjodid eine schwache Trübung, obwohl die Flüssigkeit jetzt ganz farblos war, nicht bitter schmeckte und mit kaustischem Natron oder mit Chlor und Ammon 'keine Reaction mehr zeigte. Die Auslaugung ward nicht weiter fortgesetzt, da die Reaction mit Kaliumquecksilberjodid jetzt dieselbe blieb.

Bei Verarbeitung der $500 \mathrm{CC}$. der ersten Ausziehung wurden erhalten $0,635 \mathrm{Grm} .=66,42$ Proc.; die der zweiten Ausziehung lieferten $0,055 \mathrm{Grm} .=5,75$ Proc.

Bei Verarbeitung des dritten sauren Auszugs wurden nur unwägbare Spuren abgeschieden, die aber nach Auflösung in Salzsäure mit Chlor und Ammon deutlich die grasgrüne Farbe zeigten.

Noch einmal wurden dieselben Mengen Chinaalkaloide dem Rückstande der China von dem zweiten Versuche zugesetzt und ganz auf die gleiche Weise verfahren.

Die 500 CC. der ersten Operation lieferten $0,69 \mathrm{Grm}$. Alkaloide $=72,17$ Proc.; die der zweiten Operation lieferten 0,11 Grm. $=$ 11,50 Proc.; die der dritten Opera'ion lieferten 0,02 Grm. = 2,09 Proc.; also im Ganzen erhalten 0,82 Grm. Alk lloide $=85,76$ Proc.

Die Alkaloide der dritten Ausziehung gaben wieder mit Chlorwasser und Ammon die grüne Färbung und mit Jodkalium sofort einen weissen krystallinischen Niederschlag. Das Ausziehen ward nicht weiter fortgesetzt. Da unter dem Einflusse der Salzsäure Umsetzung der Basen und vielleicht Ammoniakbildung stattgefunden haben konnte, so ward hierauf jeder der Auszüge, auch in concentrirtem Zustande, mit dem bekannten aus einer Lösung von Kaliumquecksilberjodid und 
Aetzkali bastehenden Reagens untersucht, ohne dass eine Spur entdeckt werden konnte.

Dass wirklich durch die angewandten Lösungs- und Fällungsmittel keine Zersetzung bewirkt worden war, darf aus folgenden Experimenten abgeleitet werden.

Dieselbe Menge Chinabasen, also im Ganzen $0,956 \mathrm{Grm}$., wurden wieder wie oben innig mit 25 Grm. geglühten Sandes vermischt, auf einem Wasserbade getrocknet und denselben Behandlungsweisen unterworfen. 375 CC. Flüssigkeit waren gesammelt als schon keine Spur von Reaction auf. Alkaloide, auch nicht mit Kaliumquecksilberjodid wahrzunehmen war: $0,965 \mathrm{Grm}$, wurden erhaiten, also 0,009 Grm. zu viel, was durch in dem Sande vorhandene in Salzsäure lösliche und durch Natronlauge fällbare Stoffe verursacht wurde, unter denen Spuren von Eisen vorkamen, welche die hellgelbe Färbung der salzsauren Lösung zu Wege brachten.

Die schliessliche Folgerung aus meiner jetzt angestellten Untersuchung in Betreff der Rabourdin'schen Methode ist also die, dass das Ausziehen von Chinarinde bei gewöhnlicher Temperatur mit 4 Proc. Salzsäure enthaltendem Wasser höchst mangelhaft und unvollständig stattfindet, so dass eine relativ grosse Menge Alkaloide zurückbleibt; in welchern Zustande ist mir gänzlich unbekannt. Nur eine eigens vorgenommene Untersuchung in dieser Hinsicht wurde vielleicht die richtige Antwort auf diese Frage liefern können.

Obschon also das Ausziehen der Alkaloide aus der Chinarinde durch Kalk und Alkohol sehr schwer von Statten geht, so ist es doch unbestreitbar, dass sie vollständiger stattfindet als durch das salzsäurehaltige Wasser, wie die Gesammtmenge der Alkaloide ergibt, welche nach beiden Methoden erhalten wurde.

Sollte ich wieder eine Chinarinde untersuchen, so würde ich nach de Vrij mit Alkohol und Kalk auskochen, aber die Behandlung wiederholt und so lange fortsetzen, bis sich mir bei der Untersuchung deutlich ergeben hätte, dass der Rückstand nur unbedeutende Mengen von Alkaloiden zurückbielte. Nach dem Verdampfen der mit Essigsäuce übersättigłen alkoholischen Flüssigkeit, dem Lösen in Wasser und Filtriren, würde ich mit Natronlange fällen und ferner die Abscheidung der Farbstoffe durch Lösung in Salzsäure und fractionirtes Fällen mit Ammon bewirken; die Alkaloide endlich in Alkohol lösen, in einem tarirten Platingefässe verdampfen, trocknen und wägen.

Da Chinidin und in höherem Maasse Chinin in reinem Wasser etwas löslich sind, so ist es empfehlenswerth nach der Fällung mit 
Natronlauge und dem Auswaschen des Niederschlags, das Waschwasser, sobald diess nicht mehr stark alkalisch reagirt und einen schwach bitteren Geschmack anzunehmen beginnt, für sich aufzufangen, mit Aether zu schütteln, die ätherische Lösung abzuscheiden, zu verdampfer und den Rückstand mit dem Niederschlage zu vereinigen und weiter zu behandeln.

III, Verhalten der Chinaalkaloide zu Seignettesalzund GlaủbersalzIösungen.

In dem dritten Jahrgang pag. 382 dieser Zeitschrift *) und in den meiston übrigen Zeitschriften auf chemischem und pharmaceutischem Gebiete ist eine Mittheilung von C. Mann in St. Petersburg aufgenommen, die zum Zwecke hat Chinin auf Chinidin und Cinchonidin zu prüfen uud beim Vorhandensein der beiden letzteren die Menge derselben zu bestimmen.

Die zu dem Zwecke von ihm befolgte Methode soll auf einem versehiedenen Verhalten der Chinabasen zu Seignettesalz- und Glaubersalzlösungen beruhen. Vgl. den angeführten Artikel a. a. 0. Seite $382-384$.

Wie schon zu Anfang von mir bemerkt wurde, prüfte ich die dort angegebene Methode, um vielleicht auf diesem Wege eine Trennung der Chinaalkalojde bewirken zu können.

Denn wäre die Angabe richtig und also schwefelsaures Chinidin und schwefelsaures Cinchonin in Seignettesalz löslich, schwefelsaures Chinin und Cinchonidin darin unlöslich, während von den beiden letzteren nur schwefelsaures Cinchonidin in der Lösung von schwefelsaurem Natron löslich sein würde, das schwefelsaure Chinin aber nicht, so lag die Möglichkeit einer Trennung durch das Verwandeln sämmtlichẹ Alkaloide in Sulfate und das Ausziehen dieser mit der Seignettesalzlösung auf der Hand. Der Rückstand, schwefelsaures Chinin und schwefelsaures Cinchonidin, würde dann mit der Lösung von schwefelsaurem Natron behandelt und getrennt werden können.

Sehr bald ergab sich mir jedoch, dass die ganze Methode auf einer Mystification, einer ungenauen Beobachtung und einer unerklärlichen Oberflächlichkeit beruht, während der Anwendung für die quantitative Bestimmung vielleicht nur theoretische Speculation, aber keine praktische Ausführung zu Grunde liegt.

Wird schwefelsaures Chinidin bei der genannten Temperatur mit einer Seignettesalzlösung von der angegebenen Stärke agitirt, so löst

*) Im Bericht über die qualitative Ermittelung organischer Körper. D. Red. 
sich eben so viel wie in Wasser von derselben Tenperatur. Eine genaue vergleichende Untersuchung mit gesättigten Lösungen unter Anwendung von Ammon und von Chlorwasser und Ammon als Reagentien liess keinen Unterschied wahrnehmen. Beide Lösungen unterschieden sich nur dadurch, dass die in Wasser fluorescirte, die in der Seignettesalzlösung nicht, aus letzterer schieden sich nach Verlauf einiger Zeit kleine Krystalle von weinsteinsaurem Chinidin ab. Anders war das Verhalten beim Anwenden einer concentrirten Lösung von Seignettesalz. 0,5 Grm. schwefelsaures Chinidin wurden in einem Mörser mit einer gesättigten Seignettesalzlösung agitirt, doch obgleich $175 \mathrm{CC}$. hiervon verwandt worden waren, blieben noch 0,05 Grm. zurück, von denen nichts mehr gelöst wurde, während aus der Flüssigkeit durch Ammon 0,25 Grm. Niederschlag abgeschieden ward, der sich wie reines Chinidin verhielt. Was bei Behandlung mit der Seignettesalzlösung nicht gelöst worden war, zeigte mit Wasser gekocht eine schwach alkalische Reaction. Die wässerige Lösung enthielt keine Schwefelsäure, ward durch Seignettesalz gefällt und brachte mit essigsaurem Bleioxyd einen krystallinischen, in Essigsäure löslichen und mit Jodkalium gleichfalls einen krystallinischen Niederschlag hervor. Beim Lösen in Salzsäurc entstand durch Chlorwasser und Ammon die grasgrüne Färbung, und sowohl durch Jod, Alkohol und Schwefelsäure als durch Jod, Essigsäure und Schwefelsäure, die für Chinidin charakteristischen granatrothen Krystalle.

Nach dem Filtriren und Erkalten der kochenden wässerigen Lösung schieden sich Krystalle ab, die in Alkohol löslich, in Aether unlöslich waren und sich mit weinsteinsaurem Chinidin vollkommen identisch verhielten. Es hatte also Umsetzung, Bildung von schwefelsaurem Natron-Kali und weinsteinsaurem Chinidin stattgefunden, welches letztere in Seignettesalz ganz unlöslich ist. Setzt man also einer Lösung von schwefelsaurem Chinidin selbst in Wasser, eine starke Lösung von Seignettesalz za, so entsteht ein Niederschlag von weinsteinsaurem Chinidin.

Ebenso verhält sich schwefelsaures Cinchonin; in der Seignettesalzlösung $(1: 10)$ löst sich eher etwas weniger als in reinem Wasser und allmählich sieht man einen krystallinischen Niederschlag von weinsteinsaurem Cinchonin sich abscheiden. Dass diess unter gleichen Umständen bei schwefelsaurem Chinidin nicht so schnell und eben so wenig in demselben Maasse stattfindet, ist dem Umstand zuzuschreiben, dass das schwefelsaure Cinchonin sich viel leichter and in grösserer Menge auföst, als das schwefelsaure Chinidin. Mit einer gesättigten Seignettesalzlösung gibt.die wässerige Solutión des schwefelsauren Salzes einen 
Niederschlag. Es findet wieder Bildung und Abscheidung von weinsteinsaurem Cinchonin statt. Die Löslichkeit desselben in dem Seignettesalz ist also auch bier scheinbar.

Auch die wässerige Lösung von schwefelsaurem Cinchonidin ward durch Seignettesalz gefällt.

Dasselbe gilt von schwefelsaurem Chinin. Wegen seiner geringen Löshichkeit in Wasser fand eben so wenig scheinbare als wirkliche Lösung statt. Nur Spuren konnten nachgewiesen werden.

Was die Löslichkeit des schwefelsauren Cinchonidins in einer Glaubersalzlösung betrifft, so war auch diese nur scheinbar und von der in reinem Wasser nicht verschieden, wie sich diess ergab durch Vergleichung von unter gleichen Umständen bereiteten gesättigten Lösungen in Wasser und in der schwefeisauren Natronlösung, in welchen beiden durch Ammon ein im Volumen vollkommen übereinstimmender Niederschlag entstand.

Das Glauber'salz hatte also zu dieser Löslichkeit nichts beigetragen. Schwefelsaures Cinchonin und schwefelsaures Chinidin verhielten sich auf die nämliche Art sowie auch schwefelsaures Chinin; da das letzte Salz in Wasser nur sehr wenig löslich ist, so löste es sich also auch in der Glaubersalzlösung in geringer Menge auf. Nach dem Niederschlage zu urtheilen; welchen Ammon in den filtrirten Lösungen hervorbrachte, war das schwefelsaure Cinchonin in reinem Wasser ebenso gut löslich als in der schwefelsauren Natronlösung.

Bei Vergleichung der Löslichkeit des schwefelsauren Chinins in Wasser, in einer Seignettesalzlösung und in einer Glaubersalzsolution ergab sich durch Chlorwasser und Ammon, dass das erstgenannte Lösungsmittel die grösste Menge enthielt; das Seignettesalz hatte beinahe nichts gelöst, während die Flüssigkeit Schwefelsäure enthielt; es war also in der Seignettesalzsolution unlösliches weinsteinsaures Chinin entstanden.

In der Glaubersalzlösung war auch etwas aufgelöst, doch weniger als im Wasser, da die Reaction weniger stark und auch der Niederschlag mit Ammoniak schwächer war; das schwefelsaure Chinin ist also in Glaubersalz enthaltendem Wasser noch weniger löslich als in reinem Wasser.

Obenstehende Versuche erschienen mir ausreichend um deutlich nachzuweisen, dass auf diesem Wege keine befriedigende Trennung der Chinaalkaloide zu elwarten war. 


\section{Verhalten der Chinaalkaloide zu einer Kalium- platincyanürlösung.}

Delffs *) lenkte die Aufmerksamkeit der Chemiker auf ein bisher nicht benutztes Reagens, das Kaliumplatincyanür, das nicht allein zu einer Unterscheidung der Chinaalkaloide, sondern auch für die Diagnose der organischen Basen überhaupt, besonders geeignet genannt wird. Das Reagens soll den doppelten Vortheil darbieten, dass nur einige Alkaloide durch dasselbe aus ihren löslichen Verbindungen mit Säuren gefällt werden, und dass diese Niederschläge, soweit sie bisher geprüft worden sind, sich in heissem Wasser lösen und sich beim Erkalten wiederum in charakteristischen, mikroskopisch erkennbaren Formen ausscheiden. $\mathrm{Zu}$ den fällbaren Alkaloiden gehören das Cinchonin und Chinidin, zu den nicht fäl1 baren das Chinin und das Cinchonidin (!).

Die krystallisirte Cinchonin-Verbindung soll der Formel $\mathrm{C}_{40} \mathrm{H}_{22}$ $\mathrm{N}_{2} \mathrm{O}_{2}+\mathrm{HCy}+\mathrm{PtCy}+3 \mathrm{HO}$ entsprechen. Dieselbe schmilzt bei vorsichtigem Erhitzen zu einer violetten Flüssigkeit, welche sich bei etwas gesteigerter Temperatur schwärzt.

Die krystallisirte Chinidin-Verbindung, deren Analyse noch nicht vollendet war, gleicht im äusseren Ansehen dem Gentisin; ihre gelbliche Farbe ist indessen etwas blasser.

Weiter wird noch etwas über eine Brucin-Verbindung bemerkt und über diesen Gegenstand für die Folge weitere Mittheilungen versprochen, die jedoch, soweit mir bekannt ist, noch nicht erschienen sind.

Ich will gleich zu Anfang bemerken, dass 1. Delff's Angabe ungenau ist, da nicht nur Cinchonin und Chinidin, sondern auch Chinin und Cinchonidin von dem Reagens niedergeschlagen werden.

2. dass die Formel der Cinchoninverbindung eben so wenig richtig dargestellt ist (siehe unten) und

3. dass schon früher Cinchoninplatincyanür dargestellt und zu gleichem Zwecke das Kaliumplatincyanür empfohlen wurde.

In einer Abhandlung von Martius nämlich «Ueber einige Cyanverbindungen der Platinmetalle»**) ward dieses Salz durch Fällen einer kochenden Lösung von Baryumplatincyanür mit schwefelsaurem Cinchonin dargestellt, wodurch voluminöse, farblose, nadelförmige Kryställchen entstanden, die wasserfrei, in Alkohol auflöslich und in Wasser schwerlöslich waren. Beim Erhitzen schmolzen sie zu einer rothbraunen

*) Diese Zeitschrift B. 3. pag. 152 (im Bericht über die qualitative Ermittelung organischer Körper).

**) Ann. d. Chem. u. Pharm. B. 11\%, pag. 376. 
Masse, die in höherer Temperatur verkohlte und dichtes metallisches Platin hinterliess.

0,3802 Grm. Substanz gaben 0,0810 Grm. Pt. $=21,38 \mathrm{pC}$, was der Formel PtCy, ChnCy entspricht, die 21,57 pC. Metall erfordert.

Obschon im Folgenden kein directer Beweis dafür geliefert wird, so darf doch, wenn man die mit Wasserzersetzung verbundene Operation in Betracht zieht, mit grösserer Wahrscheinlichkeit angenommen werden, dass kein Cinchonincyanür, aber wohl ein Cinchonincyanwasserstoff in der Verbindung vorkam. Hinsichtlich der verschiedenen Löslichkeit in Wasser und Alkohol muss ich bemerken, dass diess, wie unten durch das Experiment bestätigt werden soll, nur für die gewöhnliche Temperatur gilt; bei Siedehitze stimmt diese Löslichkeit sehr überein.

Ueber die Verwendung von $\mathrm{KaCy}, \mathrm{PtCy}$ als Reagens gibt $\mathrm{Sch}$ warzenbach *) hinsichtlich der Chinaalkaloide Folgendes an:

Schwefelsaures Chinin unter Zusatz cines Tröpfchens Schwefelsäure in Wasser gelöst erzengt mit dem genannten Reagens sofort einen sehr reichlichen rein weissen Niederschlag, der sich bei mikroskopischer Untersuchung als ganz amorph erwies, aber nach Verlauf von 3 Stunden krystallinisch geworden war; an die Stelle der formlosen Körnchen waren kleine krystallinische Tafeln und kurze Säulchen getreten. Auch eine vollkommen neutrale Lösung von salzsaurem Chinin wurde sogleich weiss und amorph gefällt; dieser Niederschlag war jedoch nach Verlauf ron 3 Stunden noch nicht krystallinisch.

In einer späteren Abhandlung **) wird dieselbe Sache von Schw arzenbach nochmals, und zwar ausführlicher, besprochen. Die in einer schwefelsäurehaltigen Lösung von schwefelsaurem Chinin erzengten Krystalle wurden genau untersucht, und es ergab sich dabei, dass sie scheinbar in 3 verschiedenen Formen vorkamen, nämlich: 1 . in grossen, bündelförmig vereinigten, durchsichtigen Tafeln, die namentlich durch parallele Streifen charakterisirt sind; 2. in warzigen, aus Anhäufungen von kurzen Prismen oder breiten Nadeln bestehenden Massen; der 3. Theil des Niederschlags ist wie Schwarzenbach sagt gewöhnlich ganz amorph und bildet eine harzige, durchscheinende Masse, an der nur selten ein krystallinisches, undeutlich nadelförmiges Gewebe wahrgenommen wird.

*) Wittsteins Vierteljahresschrift f. pract. Pharm. B. 6. pag. 422.

**) Ebendaselbst B. 8, pag. 518. 
Offenbar hat also Schwarzenbach keine reinen Krystalle untersucht, sondern ein Gemenge eines krystallinisehen und eines amorphen Niederschlags. Die tafelförmigen Krystalle lösten sich in siedendem Wasser, schieden sich aber beim Erizalten grossentheils wieder ab, entweder in der vorigen Form oder in kleinen glänzenden Blättchen; durch plötzliches Abkühlen, wie z. B. durch Filtriren in ein kaltes Glas u. s. w., ward die Lösung milchig trübe, doch wurde der so abgeschiedene Niederschlag nach Verlauf einiger Stunden wieder krystallinisch. Die wässerige Lösung gab mit Chlorwasser und Ammoniak die bekannte grüne Farbe als Reaction für Chinin. Die drei erhaltenen Formen wurden von einander getrennt und analysirt.

a. Die lufttrocknen tafelförmigen Krystalle nahmen geraume Zeit hindurch auf $100-120^{\circ} \mathrm{C}$, erhitzt an Gewicht nicht ab; bei $150^{\circ} \mathrm{C}$. dagegen $6,35 \%$. Bei dieser Temperatur nahmen die Krystalle eine hochgelbe Farbe an, die beim Erkalten grossentheils wieder verschwand. Firner wurde noch der Gehalt an Platin durch Erhitzen in einem Platingefässe bestimmt und aus beiden Daten die Formel $\mathrm{Ch}^{+} \mathrm{CyH}$, PtCy $+2 \mathrm{HO}$ abgeleitet, worin für $\stackrel{\stackrel{+}{\mathrm{Chn}} \mathrm{C}_{20}}{\mathrm{H}_{12}} \mathrm{NO}_{2}$ angenommen wird. Verdoppeln wir also diese Formel, da von uns $\mathrm{C}_{40} \mathrm{H}_{24} \mathrm{~N}_{2} \mathrm{O}_{4}$ als Zusammensetzung des Chinins angenommen worden ist, so wird sie

$$
\mathrm{C}_{40} \mathrm{H}_{24} \mathrm{~N}_{2} \mathrm{O}_{4}, 2 \mathrm{HCy}, 2 \mathrm{PtCy}+4 \mathrm{HO} \text {. }
$$

Ich habe Grund dis Richtigkeit dieser Formel hinsichtlich des Wassergehaltes zu bezweifeln.

Dieselben Krystalle wie die, welche der Verfasser im Auge hatte und die bei mikroskopischer Betrachtong eine gleiche Gestalt zeigten, sind eigens wiederholt in dieser Richtung untersucht worden. Wie gleich nachher angegeben werden soll, hatte nach mehrstündigem Erhitzen bei einer zwischen 150 und $155^{\circ}$ gelegenen Temperatur noch durchaus keine Gewichtsabnahme stattgefunden, und hatte sich das äussere Ansehen keineswegs verändert; erst später, bei höherer Temperatur, entwich einiges Wasser und waren die Krystalle hellgelb gefärbt, welche Färbung Stand hielt; die Zersetzung hatte also begonnen.

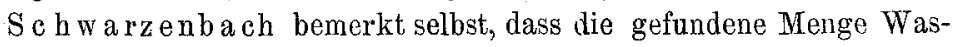
ser zu hoch ist um der Formel zu entsprechen, spricht aber die Ueberzeugung aus, dass, wenn die Krystalle erst über Schwefelsäure getrocknet worden wären, sie noch eine kleine Menge nicht zu den Krystallen gehörigen Wassers verloren haben würden.

Doch wie lässt sich diese Ueberzeugung mit der Thatsache reimen, dass die analysirten Krystalle geraume Zeit hindurch bei $100-120^{\circ}$ C. erhitzt an Gewicht nicht abnahmen? Wäre anbängendes Wasser zu- 
gegen gewesen, so hätte diess ja bei dieser Temperatur entweichen müssen.

Teberdiess sagt der Verfasser, dass die beim Erhitzen entstandene gelbe Färbung beim Erkalten grossentheils, also nicht ganz verschwand; ein Theil der Verbindung hatte also eine beginnende Zersetzung erlitten und wird vermutblich den relativ geringen Wasserverlust verursacht haben.

Auf Grund dieser Betrachtungen in Verbindung mit dem Resultate meiner Analyse glaube ich behaupten zu dürfen, dass die Krystalle nicht 4 Aeq. HO enthaiten.

b. Für die Bündel von Prismen oder breiten Nadeln, die jedoch nach dem Verfasser unter dem Mikroskope grosse Uebereinstimmung mit den tafelförmigen Krystallen zeigten, sich in kochendem Weingeiste lösten und beim Erkalten unverändert abschieden, wird die Formel

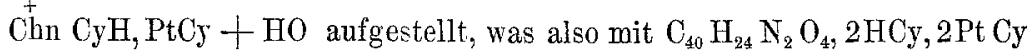
$+2 \mathrm{HO}$ übereinstimmt, allein auf den Grund hin, dass bis zu einem constanten Gewichte über Schwefelsäure getrocknete Krystalle 30,427 Proc. Platin hinterliessen. Dass keine directe Wasserbestimmung stattfand, kann man aus der Bemerkung schliessen, welche Schwarzenbach macht, dass auch diess Wasseratom bei erhöhter Temperatur ohne Zweifel werde verjagt werden können.

Was das Verhalten zu Alkohol betrifft, so stimmen die tafelförmigen Krystalle in dieser Beziehung ganz mit den prismatischen überein.

c. Die harzige, in siedendem Wasser zu Kügelchen schmelzende Masse hinterliess über Schwefelsåure getrocknet 30,4 Proc. Platin, löste sich aber in mässigen Mengen Weingeist auch nach langem Kochen nicht auf. Aus beidem wird geschlossen, dass diese amorphe Masse dieselbe Zusammensetzung hat wie $b$, aber in der Löslichkeit abweicht, welche Differenz Schwarzenbach mit ihrer Formverschiedenheit in Verbindung bringt.

In Betreff des vermeintlichen Wassergehaltes muss ich meine so eben gemachte Bemerkung wiederholen : er ist nicht durch directen Versuch gefunden. Der Unterschied in der Löslichkeit ist ebensowenig bewiesen; der Verfasser sagt nicht, was er unter mässigen Mengen Weingeistes versteht, gibt keine Dichte desselben an und bemerkt auch nichts von einer eigens angestellten Untersuchung der alkoholischen Flüssigkeit, die allein hätte entscheiden dürfen. Unten wird sich ergeben, dass die Verbindung sich selbst in siedendem Alkohol von 0,8 spec. Gew. sehr schwer löst. Ohne nähere Untersuchung wird man 
also leicht zu dem Glauben gebracht werden, dass sie in diesem Lösungsmittel unlöslich sei.

Weiter wird noch von Schwarzenbach eines besondern Verhaltens Erwähnung gethan, welches diess Reagens zeigt, wenn man das Chinin statt in Schwefelsäure in Essigsäure auflöst. Diess Verhalten wurde jedoch von mir nicht studirt.

Schon früher *) im Jahre 1850 ist von Wertheim berichtet worden über eine Doppelverbindung von cyanwasserstoffsaurem Chinin mit Platincyanür $=\stackrel{+}{+} \mathrm{Chn} C y H+P t C y+1$ aq. und über eine aus chlorwasserstoffsaurem Chinin mit Platincyanid bestehendes Doppelsalz = $\stackrel{+}{\mathrm{Ch}} \mathrm{ClH}+\mathrm{PtCy}_{2}$, die beide durch Fällang der Lösung von schwefelsaurem Chinin mittelst der Lösungen der entsprechenden Kalisalze dargestellt worden waren, und zu dem Zwecke analysirt wurden um die Richtigkeit der Liebig'schen Formel für Chinin $\mathrm{C}_{20} \mathrm{H}_{12} \mathrm{NO}_{2}$ zu beweisen. Die Analyse, auf welche sich Wertheim stützt, ist nicht angegeben, wird aber in einer weiteren Mittheilung versprochen, nach der ich jedoch vergebens gesucht habe. Die Formel für die Hydrocyanverbindung verdoppelt ergibt:

$$
\mathrm{C}_{40} \mathrm{H}_{24} \mathrm{~N}_{2} \mathrm{O}_{4}, 2 \mathrm{HCy}, 2 \mathrm{Pt} \mathrm{Cy}+2 \mathrm{HO} \text {. }
$$

Da die analytischen Data fehlen, so darf auch hier auf Grund des oben Gesagten die Richtigkeit der Formel hinsichtlich des Wassergehaltes bezweifelt werden, und dass die Zusammensetzung dieser Verbindung für die Berechtigung von Liebigs Formel für das Chinin keinen ausreichenden Beweis liefert, wird sofort deutlich werden, wenn sich ergeben haben wird, dass es auch ein Salz $\mathrm{C}_{40} \mathrm{H}_{24} \mathrm{~N}_{2} \mathrm{O}_{4}, \mathrm{HCy}, \mathrm{PtCy}$ gibt, welches von gleicher Beweiskraft für die Richtigkeit der Formel $\left.\mathrm{C}_{40} \mathrm{H}_{24} \mathrm{~N}_{2}^{*} \mathrm{O}_{4} * *\right)$ ist.

*) Ann. d. Chem. u. Pharm. B. 73, pag. 208.

**) Von der Oberflächlichkeit und Mangelhaftigkeit, womit oft Mittheilungen Anderer herübergenommen werden, liefert Folgendes ein Pröbchen:

In Gerhardt's Traité de Chimie organique T. IV. p. 121 werden, mit Verweisung auf die Originalabhandlung, Wertheims beide Cyanoplatinate in folgenden Worten angegeben:

"Nach Herrn Wertheim erhält man die folgenden Salze:

a. $\mathrm{C}_{40} \mathrm{H}_{24} \mathrm{~N}_{2} \mathrm{O}_{4}, 2(\mathrm{CyH}, \mathrm{PtCy})+2$ aq.

ק. $\mathrm{C}_{40} \mathrm{H}_{24} \mathrm{~N}_{2} \mathrm{O}_{4}, 2$ ( $\mathrm{ClH}, \mathrm{Pt} \mathrm{Cy}_{2}$ ), indem man das Chininsulfat durch die entsprechenden Kalisalze fällt." Die Formeln sind also verdoppelt.

In dem ausführlichen Traité de Chimie von Pelouze und Frémy, $3^{\circ}$ édition T. IV. Chim organ. p. 586 steht, ohne Angabe der zu Rathe gezoge- 
Fassen wir also noch einmal kurz die uns bekannte Geschichte der Hydrocyanverbindungen der Chinabasen zusammen, so kommen wir zu dem Schlusse, dass ein saures cyanwasserstoffsaures Chinin-Platincyanür zuerst von Wertheim und dann von $\mathrm{Schwar} z$ en bach dargestellt wurde; dass letzterer zuerst die Eigenschaften desselben angab, später von Delffs das Vorhandensein dieser Chininverbindung geleugnet und von ihm ein schon früher von Martius dargestelltes neutrales cyanwasserstoffsaures Cinchonin-Platincyanür angenommen ward, wobei Delffs zugleich mit einem Worte einer nicht analysirten Chinidinverbindung Erwähnung thut.

Ehe ich zu der Angabe meiner Versuche übergehe, sei bemerkt, dass . mir bei der Darstellung des Kaliumplatincyanürs (des Gmel i n'schen

nen Quelle, unter der Teberschrift "Platinocyanates de quinine" Folgendes verzeichnet : "Es gibt zwei Chininsalze, die den Formeln $\mathrm{C}_{20} \mathrm{H}_{12} \mathrm{NO}_{2}, \mathrm{HCy}, \mathrm{PtCy}$, $2 \mathrm{HO}$ und $\mathrm{C}_{20} \mathrm{H}_{12} \mathrm{NO}_{2}, \mathrm{HCy}, \mathrm{PtCy}_{2}$ entsprechen, und welche man erhält, indem man das Chininsulfat durch die entsprechenden Kalisalze fällt."

Wenn man erwägt, dass wir das zweite Sals nirgends erwähnt finden, und der Text so gut wie wörtlich herübergenommen ist, so wird die Vermuthung, dass aus Gerhardt's Lehrbuch geschöpft wurde, wohl nicht gewagt oder kühn genaunt werden. Aber wie wurde herübergenommen? P el ouze und Frémy sind Anhänger der Formel $\mathrm{C}_{20} \mathrm{H}_{12} \mathrm{NO}_{2}$ für Chinin; die Formeln Gerhardt's mussten also in Uebereinstimmung hiermit abgeändert werden, was auch geschah, jedoch ohne dass diess auf den Wassergehalt angewandt wurde; statt $1 \mathrm{Aeq}$. HO hat man deren 2 beibehalten; bei der zweiten Formel ist nur übersehen, dass von einer Verbindung zwischen salzsaurem Chinin und Platincyanid und nicht von einem Hydrocyanat dieser Base gesprochen wird.

Merkwürdig ist noch der Curiosität wegen was wir drei Seiten weiter pag. 589 ron Chinidin angegeben sehen:

"Das Chinidin lässt sich rermittelst folgender Reaction vom Chinin und Cinchonin unterscheiden: wenn man es fein pulvert und mit Chlor behandelt, löst es sich, und durch Zusatz von Ammonials erleidet diese Lösung keine Veränderung, während unter den nämlichen Umständen das Chinin unter dem Einflusse des Ammoniaks eine grüne Färbung und das Cinchonin einen Niederschlag gibt;"

während es allgemein bekannt ist, dass Chinin und Chinidin gerade hinsichtlich dieses Verhaltens zu Chlorwasser und Ammon ganz identisch sind.

Dass dergleichen, zufällig entdeckte, verstümmelte und schiefe Darstellungen für die Tüchtigkeit des sonstigen Inhaltes des volumainösen Werkes wèng Garantie liefern, wird wohl keines Beweises bedürfen. 
Salzes) folgende, in der Hauptsache mit der Knop's ïbereinstimmende Methode sehr empfehlenswerth erschienen ist:

Erhitzen des Platinchlorids in einem Porcellanschälchen über einer kleinen Gasflamme auf nicht mehr als $230^{\circ} \mathrm{C}$. unter Umrühren mit einem Thermometer. Wird bei dieser Temperatur kein Chlor mehr verjagt, so hat sich das Salz in ein graugrünes Pulver verwandelt, dem man allmählich unter Erwärmung eine wässerige Lösung von so viel Cyankalium zusetzt als sich Platinchlorür gebildet hat; welches sich dann löst und nach dem Filtriren der kochenden Lösung beim Erkalten krystallisirt. Zum Entfernen von anhängendem Chlorkalium wurden die Krystalle einigemal umkrystallisirt. Die vorgeschriebene Menge Cyankalium ist gegründet auf die Gleichung:

$$
\mathrm{PtCl}+2 \mathrm{KaCy}=\mathrm{KaCy}, \mathrm{PtCy}+\mathrm{KaCl} .
$$

Das Aequivalentgewicht von Platinchlorür ist $=134,5$, das von 2 Aeq. Cyankalium $=130$; verwendet man also von beiden gleiche Mengen, so ist ein wenig Cyankalium im Ueberschuss, was für die Krystallisation des Salzes von Vortheil ist. Diese Methode verdient den Vorzug vor der, nach welcher Platinschwamm mit gelbem Blutlaugensalze erhitzt wird, weil dann nur ein kleiner Theil des Metalls in die gewünschte Verbindung übergeführt wird; die grösste Menge bleibt (wahrseheinlich an Eisen gebunden) zarüek, ohne beim Erhitzen mit einer neuen Menge Blutlaugensalz wieder etwas ven der Doppelverbindung zu erzeugen.

Ueberdiess lässt sich das Salz, wenn man es auf diesem Wege darstellt, trotz der Behandlung mit Alkohol schwer ganz von geringen Mengen Blutlaugeasalz befreien, was doch von der grössten Wichtigkeit ist, da auch diess mit den Chinaalkaloiden unlösliche Verbindungen liefert.

Ein schön krystallisirtes Kaliumplatincyanür, welches anf diese Weise bereitet war, und in dem man so ohne Weiteres keine Unreinigkeiten vermuthet haben würde, war ziemlich stark damit verunreinigt.

Für die Analyse des reinen Salzes wurden zur Wasser- und Pla* tinbestimmung 0,848 Grm. genommen, welche 0,106 Grm. Wasser verloren $=12,5$ Proc. Beim Glühen des übrig gebliebenen wasserfreien Salzes in einem Porcellantiegel und Auslangen mit Wasser wurden 0,342 Grm. Platin $=40,33$ Proc. erhalten. Zur Stickstoffbestimmung wurden 0,429 Grm. mit Natronkalk verbrannt und 0,059 Grm. Ammoniak $=0,0486$ Grm. Stickstoff $=11,33$ Proc, erhalten.

Also : 


\begin{tabular}{llrl}
\multicolumn{2}{c}{ erhalten. } & berechnet *). \\
Wasser & 12,50 & 12,44 & Proc. \\
Platin & 40,33 & $45,62 \quad "$ \\
Stickstoff & 11,33 & $12,90 \quad "$
\end{tabular}

Der Wassergehalt und die Menge des Stickstoffs waren (mit Berücksichtigung dessen, was unten folgen wird) als hinlänglich genau anzusehen. Aber die Menge des Platins liess zu wünschen übrig. Bei der Untersuchung ergab sich jedoch, dass, da die Zersetzung nicht leicht vor sich geht, ein Theil der Verbindung bei dem Erhitzen unverwandelt geblieben und in das Waschwassar übergeführt worden war, wesshalb eine zweite Analyse nicht für nöthig erachtet, sondern die Formel $\mathrm{KaCy}, \mathrm{PtCy}+3 \mathrm{HO}$ als richtig betrachtet wurde.

1. Zuerst wurden nun die (durch Schütteln mit einem Ueberschusse des Sulfates bei gewöhnlicher Temperatur und Filtriren dargestellten) wässerigen Lösungen der Sulfate der Chinalkaloide geprüft.

Schwefelsaures Chinin gab einen schwachen weissen Niederschlag, der beim Erwärmen verschwand; beim Erkalten opalisirte die Flüssigkeit.

Schwefelsaures Chinidin liess einen reichlichen weissen Niederschlag entstehen, der beim Erwärmen verschwand und sich beim Erkalten als eine harzige Masse abschied, die bei mikroskopischer Betrachtung keine krystallinische Structur zeigte.

Schwefelsaures Cinchonin gab einen sehr reichlichen weissen Niederschlag, der beim Erwärmen verschwand; beim Erkalten schied sich ein weisser ikrystallinischer Niederschlag ab, der nach der mikroskopischen Betrachtung aus langen prismatischen Krystallen bestand.

Schwefelsaure Cinchonidinlösung ward reichlich, weiss gefällt; der Niederschlag löste sich beim Erwärmen auf und setzte sich nach dem Erkalten als eine amorphe Masse ab, die unter dem Mikroskop betrachtet kein krystailinisches Gewebe besass.

2. Die Lösungen der Sulfate in verdünnter Schwefelsäure gaben folgende Resultate:

Schwefelsaures Chinin einen voluminösen, weissen, durch Erwärmen löslichen Niederschlag; beim Erkalten schied sich theils ein harziges Präcipitat $a b$, theils perlmutterglänzende Blättchen, welche unter dem Mikroskop die Gestalt von breiten Prismen hatten.

*) Als $\mathrm{KaCy}, \mathrm{PtCy}+3 \mathrm{HO}$. 
Schwefelsaures Chinidin einen reichlichen weissen Niederschag, der sich durch Wärme löste; nach dem Erkalten war die ganze Flüssigkeit zu einer hellgelb gefärbten, glänzenden, federförmig krystallisirten Masse gestanden, die bei mikroskopischer Betrachtung aus langen, schmalen spiessförmigen Prismen bestand.

Schwefelsaures Cinchonin verhielt sich beim Zusatz des Kaliumplatincyanürs und Erwärmen gerade so wie schwefelsaures Cinchonidin; beim Erkalten wurde aus dem Erstgenannten ein theils harziger, theils krystallinischer Niederschlag erhalten, der ans glänzenden Nädelchen bestand, die unter dem Mikroskop die Form langer Prismen zeigten. Der Niederschlag, welcher sich nach dem Erkalten aus dem Letzteren abschied, war farblos und sowohl harzig als auch theilweise in pyramidenförmigen and prismatischen Krystallen.

3. Die wässerigen Lösungen der reinen Alkaloide gaben mit dem Kaliumplatincyanür keine Reaction, auch nicht nach Zusatz von verdünnter Schwefelsäure.

4. Die möglichst gesättigten wässerigen Lösungen der Hydrochlorate verhielten sich folgendermaassen:

Bei allen wurde ein Niederschlag wahrgenommen, der sich bei Erwärmung löste. Nach dem Erkalten hatte sich abgeschieden bei :

Salzsaurem Chinin and salzsaurem Chinidin ein weisser, harziger Niederschlag, in welchem mit dem Mikroskope keir.e Krystalle entdeckt werden konnten; bei salzsaurem Cinchonin ein krystallinisches Präcipitat von derselben Gestalt wie es aus 'schwefelsau'em Cinchonin erhalten worden war.

5. Die in verdünnter Salzsäure gelösten Hydrochlorate lieferten dieselben Resultate wie sie unter übereinstimmenden Umständen die Sulfate in der verdünnten Schwefelsäure lieferten.

6. Wird·der Mischung der wässerigen Lösungen der Sulfate und des Kaliumplatincyanürs verdünnte Schwefelsäure zugesetzt, so löst sich bei gewöhnlicher Temperatur nur der in schwefelsaurem Cinchonin entstandene Niederschlag sofort ganz, der in schwefelsaurem Cinchonidin erzeugte nur theilweise auf.

Beim Erwärmen fand wieder bei allen Lösung statt. Nach dem Erkalten hatte sich bei schwefelsaurem Cinchonin und schwefelsaurem Chinin nichts abgeschieden. Die Lösung des schwéelsauren Chinidins war fast ganz gestanden unter Erzeugung der eben erwähnten hellgelb gefärbten, seidenglänzenden Krystalle aus der des schwefelsauren Cinchonidins schieden sich langsam dreieckige, pyramidenförmige mikroskopische Krystalle ab. 
7. Setzte man dem Gemenge der Lôsungen der Sulfate in verdünnter Schwefelsäure und dem Reagens noch etwas mehr verdünnte Schwefelsäure zu, so verschwand der Niederschlag bei gewöhnlicher Temperatur bei keinem von allen, aber wohl durch Erhitzen. Nach dem Erkalten war die Chinidinverbindung wie oben und noch vollständiger abgeschieden; das Chininsalz ganz in feinen Nadeln krystallisirt; bei dem Cinchonin hatte der Niederschlag dasselbe Aussehen bebalten, während der des Cinchonidins sternförmig gruppirte Krystallnädelchen zeigte.

8. Nachdem auf dieselbe Weise dem Gemenge der wässerigen Lösungen der Hydrochlorate and des Kaliumplatincyanürs verdünnte Salzsäure zugesetzt worden war, verschwand sogleich bei gewöhnlicher Temperatur nur der in salzsaurem Cinchonin entstandene Niederschlag, and auch nur hier ward nach dem Erwärmen und Erkalten kein Niederschlag wahrgenommen. Sonst fand dasselbe statt, was im 6. Versuche beim salzsauren Chinidin angegeben ist; das salzsaure Chinin gab einen aus sternförmig gruppirten Nädelchen zusammengesetzten krystallinischen Niederschlag, der unter dem Mikroskop als aus langen Prismen bestehend erschien.

9. Das Gemerge der Lösungen der Hydrochlorate in salzsäurehaltigem Wasser und des Reagens mit einem Ueberschuss von verdünnter Salzsäure behandelt, verhielt sich ebenso wie die entsprechenden schwefelsauren Salze in dem 7. Versuche.

Die Resultate sind also, kurz zusammengefasst, folgende:

a) die wässerigen Lösungen der reinen Alkaloide geben weder als solche, noch nach Zusatz von Schwefelsäure einen Niederschlag;

b) von den in Wasser gelösten Sulfaten geben:

Cinchonin einen in verdünnter Schwefelsäure löslichen krystallinischen Niederschlag; nach dem Erwärmen und Erkalten keine Abscheidung;

Chin in schwachen amorphen Niederschlag, in verdünnter Schwefelsäure nicht merkbar löslich; nach dem Erwärmen und Erkalten keine Abscheidung;

Chinidin amorphen in verdünnter Schwefelsäure nicht merkbar löslichen Niederschlag; nach dem Erwärmen und Erkalten kryst. Präcipitat.

Cinchon id in amorphen, in verdünnter Schwefelsäure theilweise löslichen Niederschlag; nach Verlauf einiger Zeit kryst. Präc. 
c) Bei Lösung in verdünnter Schwefelsäure geben:

Cinchonin einen theils harzigen, theils krystallinischen in verdünnter Schwefelsäure nicht merklich löslichen Niederschlag; beim Erkalten ebonfalls Abscheidung;

$\mathrm{Ch}$ in in einen theils harzigen, theils krystallinischen, in verdünnter Schwefelsäure nicht merklich löslichen Niederschlag; beim Erkalten krystallinische Abscheidung;

Chinidin krystallinischen in verdünnter Schwefelsäure nicht merklich löslichen Niederschlag; beim Erkalten krystallinische Abscheidung;

Cinchonidin theils harzigen, theils krystallinischen in verdünnter Schwefelsäure nicht merklich löslichen Niederschlag; beim Erkalten ganz krystallisirt.

d) Die wässerigen Lösungen der Hydrochlorate geben von:

Cinchonin krystallinischen, in verdünnter Salzsäure löslichen

Niederschlag; nach dem Erwärmen und Erkalten kein Präc.;

Chinin amorphen, in ve:äunter Salzsäure nicht merklich löslichen Niederschlag; nach dem Erwärmen und Erkalten kryst. Präc.;

Chinidin wie Ghinin;

Cinchonidin nicht untersucht.

e) Die salzsauren Lösungen der Hydrochlorate geben von:

Cinchonin kryst, in verdünnter Salzeäure nicht merklich löslichen Niederschlag; nach dem Erwärmen und Erkalten einen theils harzigen, theils krystallinischen Niederschlag;

$\mathrm{Ch}$ in in theils harzigen, theils krystallinischen, in verdünnter Salzsäuro nicht merklich löslichen Niederschlag; nach dem Erwärmen und Erkalten kryst. Niederschlag;

Chinidin kryst. in verdünnter Salzsäure nicht merklich löslichen Niederschlag; nach dem Erwärmen und Erkalten kryst. Niederschlag;

Cinchonidin nicht untersucht.

\section{A nalyse.}

Die Wasserbestimmung geschah dadurch, dass die lufttrocknen Verbindungen erst auf dem Wasser- dann in dem Luftbade bis zur beginnenden. Zersetzung erhitzt wurden; die Bestimmung des Platins, durch Erhitzen in einer Platinschale, bis keine Gewichtsabnahme mehr wahrgenommen ward und Wägung; die Be- 
stimmung der Menge des Alkaloids durch Lösung in angesäuertem, erwärmtem Wasser und Zersetzung durch kaustisches Natron; die Cyanbestimmung war mit Schwierigkeiten verbunden; dass sich diese nicht durch salpetersaures Silberoxyd würde bewerkstelligen lassen, konnte a priori erwartet werden; eine eigens angestellte Untersuchung lehrte denn auch, dass der hierdurch abgeschiedene Niederschlag ausser Cyan und Silber auch etwas von der organischen Base und Platin enthicit. Doch auch die übrigen zu diesem Zwecke bekannten Methoden konnten nicht mit Nutzen angewandt werden, so dass nichts anderes übrig blieb als den Stickstoffgehalt dadurch zu bestimmen, dass man die Substanz verbrannte und bei der bekannten Zusammensetzung und Menge der Chinaalkaloide berechnete wie viel zu diesem Gehalte durch das Cyan beigetragen worden war. Dass auch diese Stickstoffbestimmung nicht frei von Schwierigkeiten war, wird man aus den folgenden Zeilen ersehen.

Der Kürze wegen und um Verwirrung hinsichtlich der Verbindung, deren Analyse gemeint ist, zu verhüten, muss ich im Voraus bemerken, dass sich mir das Vorhandensein von zrvei Hydrocyanplatinverbindungen einer jeden der Chinabasen ergeben hat, nämlich das eines neutralen und eines sauren Salzes; das neutrale wird in seinen rässerigen Lösungen ohne, das saure bei Anwesenheit einer verdünnten Säure (Schwefel- oder Salzsäure) erzeugt.

A. Neutrales cyanwasserstoffsaures Cinchoninplatincyanür.

Der Zersetzung wurden unterworfen:

a) Das bei gewöhnlicher Temperatur gefällte Salz;

b) die aus der kochenden wässerigen Lösung nach dem Erkalten abgesetzten Krystalls; und

c) die aus Alkohol krystallisirte Verbindung.

0,629 Grm. von a verloren unter $100^{\circ}$ kein Wasser und liessen 0,137 Grm. Platin $=21,78$ Proc. zurück.

$0,218 \mathrm{Grm}$. von $\mathrm{b}$ verloren bei dieser Temperatur ebensowenig Wasser; 0,048 Grm. Platin blieben zurück $=22,01$ Proc.

$0,612 \mathrm{Grm}$. von c gaben keinen Wasserverlust und $0,133 \mathrm{Grm}$. Platin $=21,73$ Proc.

Hieraus durfte also der Schluss gezogen werden, dass wir es in allen drei Fällen mit derselben Verbindung zu thun hatten. Zur Cinchoninbestimmung der aus dem Alkohol abgesetzten Krystalle genommen 0,239 Grm., erhalten $=0,16$ Cinchonin $=66,94$ Proc. 
Die Formel $\left(\mathrm{C}_{40} \mathrm{H}_{24} \mathrm{~N}_{2} \mathrm{O}_{2}, \mathrm{HCy}\right)$, PtCy erfordert 21,52 Proc. Platin und 66,95 Proc. Cinchonin.

Die Reaction hatte also so stattgefunden:

$$
\text { Cinch., } \mathrm{HCl}+\mathrm{KaCy}, \mathrm{PtCy}=\text { (Cinch., } \mathrm{HCy} \text { ), Pt Cy + KaCl. }
$$

Auch auf synthetischem Wege ward versucht dieses Urtheil zu rechtfertigen : $1,028 \mathrm{Grm}$. bei $100^{\circ}$ getrockneten salzsauren Cinchonins lieferten 1,028 Grm. der Doppelvarbindung, während aus dem (die wässerige Lösung des Hydrocyanats enthaltenden) Filtrate durch kohlensaure Natronlösung noch 0,077 Grm. Cinchonin gefällt wurden. In 1,028 Grm. salzsauren Cinchonins sind vorhanden:

\section{0,919 Grm. Cinchonin}

hiervon abgezogen 0,077

bleibt $0,842, "$,

welche (bei $100^{\circ}$ getrocknet) 1,213 Grm. geliefert hatten, während nach der Berechnung 1,257 Grm. hätten erhalten werden sollen. Dieses Resultat war also befriedigend. Um (mit Rücksicht anf die von Delffs aufgestellte Formel) zu bestimmen, ob auch etwa über $100^{\circ}$ Wasser entwiche, wurden $0,247 \mathrm{Grm}$. der krystallisirten Verbindrng geraume Zeit hindurch von $100-110^{\circ}$, von $110-120^{\circ} \mathrm{u}$. s. w. erhitzt und jedesmal gewogen. Bis zu $170^{\circ}$ hatte noch keine Veränderung oder Gewichtsabnahme stattgefunden; bei ungefähr $190^{\circ}$ C. begann die Zersetzung; 0,053 Grm. $=21,46$ Proc. Platin blieben zurück.

Das Wasserfreisein der Verbindung konnte also eben so wenig, als die Richtigkeit der Formel bezweifelt werden.

Für die Stickstoffbestimmung endlich wurden mit Natronkalk und ein wenig Zucker vermengt und in einer Glasröhre erhitzt: $0,371 \mathrm{Grm}$. (aus Alkohol krystallisirt), welche nur $0,0209 \mathrm{H}_{8} \mathrm{~N}=0,0172 \mathrm{~N}=4,63$ Proc. N lieferten, statt 12,17 Proc. wie es die Formel erfordert.

$0,347 \mathrm{Grm}$. (bei gewöhnlicher Temperatur gefüllt) gaben 0,0342 $\mathrm{H}_{8} \mathrm{~N}=0,0281 \mathrm{~N}=8,1$ Proc.

Diese Resultate waren also ganz verscbieden und unbefriedigend; aber welchem Umstande musste diese Anomalie zugeschrieben werden? Um in dieser für mich dunkeln Sache Licht zu erhalten, machte ich mir die Beantwortung folgender Fragen zur Aufgabe:

Sind die Umstände unter denen die Sticzstoffbestimmung gesehah (abgesehen von der besondern Eigenthümlichkeit des Hydrocyanats) günstig?

Wird der Stickstoff des Cyans ganz in $\mathrm{H}_{3} \mathrm{~N}$ umgesetzt? 
Ist diess mit dem des Cinchonins ebenso der Fall?

Von möglichst unter denselben Umständen erhitzten 0,297 Grm. Chlorammonium wurden frei $0,094 \mathrm{H}_{3} \mathrm{~N}=0,0774 \mathrm{~N}=26,06$ Proc.; die Berechnung verlangt 26,16 Proc., die Genauigkeit liess also nichts zu wünschen übrig; die erste Frage musste bejahend beantwortet werden.

$0,3315 \mathrm{Grm}$. Cyankalium lieferten $0,08316 \mathrm{Grm} . \mathrm{H}_{3} \mathrm{~N}=0,0685$ $\mathrm{N}=20,7$ Proc.; die Formel erfordert 21,5 Proc.

Diess Resultat, mit dem bei der oben erwähnten Analyse des Kaiiumplatincyanürs erhaltenen verglichen, machte es wabrscheinlich, dass auch hierin die Ursache nicht zu finden sei, sondern, dass sie nur in dem Cinchonin oder in einem besondern Verhalten der ganzen Verbindung gesucht werden müsse.

$0,429 \mathrm{Grm}$. bei $100^{\circ}$ getrocknetes Cinchonin gaben 0,0208 Grm. $\mathrm{H}_{3} \mathrm{~N}=0,0171$, Grm. $\mathrm{N}=4$ Proc. obschon 9,09 Proc. hätten erhalten werden müssen; nur die Hälfte $\mathrm{N}$ war also ungefähr als $\mathrm{H}_{8} \mathrm{~N}$ frei geworden.

Die Analyse ward nochmals mit 0,426 Grm. Cinchonin wiederholt, wovon $0,026 \mathrm{H}_{3} \mathrm{~N}$ aufgefangen wurden $=0,021 \mathrm{~N}=4,93$ Proc.

Das Mittel beider Analysen gibt 4,46 Proc.

Nehmen wir einmal für einen Augenblick an das Cinchonin habe als Zusammensetzung $\mathrm{C}_{40} \mathrm{H}_{24} \mathrm{NO}_{2}$ und enthalte also statt 2 nur 1 Aeq. $\mathrm{N}$, so würde diese Zusammensetzung mit 4,76 Proc. $\mathrm{N}$ übereinstimmen, und beruhte nicht die angenommene Formel auf Analysen von $\mathrm{Re}-$ gnault und Liebig, die anf einem andern Wege vorgenommen sind, so vï̈re es verführerisch gewesen diese Voraussetzung für richtig zu halten. Jetzt aber musste an andere, mehr zufällige Umstände gedacht werden, und an erster Stelle ward der Temperatur Aufmerksamkeit geschenkt. Dass bei der, bei welcher die Analyse geschah, kein $\mathrm{H}_{3} \mathrm{~N}$ zersetzt ward, hatte der Versuch mit $\mathrm{H}_{4} \mathrm{NCl}$ bewiesen. Eine andere Frage war es, ob die Temperatur unter den gewöhnlichen Umständen der Bestimmung, hinlänglich gesteigert wird um allen $\mathrm{N}$ in $\mathrm{H}_{3} \mathrm{~N} z u$ verwandeln.

Von 0,285 in einer glasirten Porcellanröhre erhitzten Grm. Cinchonin warden nur 0,00486 Grm. $\mathrm{H}_{3} \mathrm{~N}=0,004002$ Grm. $\mathrm{N}=1,40$ Proc. erhalten; das Resultat war also noch ungünstiger, sei es dadurch, dass $\mathrm{H}_{3} \mathrm{~N}$ oder die flüchtigen Basen trotz der Glasur durch Poren entwichen waren, sei es, dass der Inhalt der Röhre keine so hohe Temperatur angenommen hatte wie bei den zwei früheren Versuchen. Nähere Untersuchung war also doppelt nothwendig geworden. 
Die Zerlegung von $0,476 \mathrm{Grm}$. Cinchonin ward darauf in einer mit Kupferblech umwickelten Glasröhre bewerkstelligt; erhalten 0.03267 Grm. Ammoniak $=0,0269 \mathrm{~N}=5,65$ Proc., das Resultat kam also der Wahrheit näher und die Vermuthung wegen des Einflusses der Temperatur wurde wahrscheinlicher. Um diese noch mehr zu steigern ward ein Verbrennungsofen angefertigt, der

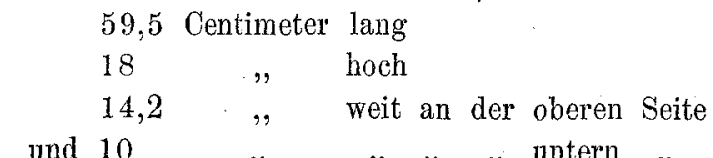

war. Der gewöhnlich "gebrauchte "Apparat hatte die folgenden Dimensionen:

$\begin{array}{lcc}\text { Länge } & 43 \text { Centime'er } \\ \text { Höhe } & 10 & , \\ \text { Weite, obere Seite } & 13,5 \quad " \\ \quad, \text { untere }, & 9 & "\end{array}$

Als nun bei Anwendung einer mit Knpferblech umgebenen Glasröhre, die ungefähr 45-50 Centimeter lang und 12 Millimeter weit war, 0,297 Grm. möglichst stark erhitzt wurden, wurden 0,0297 Grm. $\mathrm{H}_{3} \mathrm{~N}$ frei $=0,02446 \mathrm{~N}=8,24$ Proc.

Ohne dass ich nun behaupten will, dass die Hälfte $\mathrm{N}$ des Cinchonins leichter in $\mathrm{H}_{3} \mathrm{~N}$ übergeführt werden könne, so war doch durch das Voráusgehende deutlich bewiesen, dass die Stickstoffbestimmung dieses Cyanwasserstoff-Cinchoninplatincyanürs nicht auf dem gewöhnlichen Wege, sondern nur bei einem höheren Wärmegrade vorgenommen werden kann.

In dem abgeänderten Verbrennungsofen nebst Röhre wurden nun 0,405 Grm. der Hydrocyanverbindung analysirt und 0,0567 Grm. $\mathrm{H}_{3} \mathrm{~N}=0,0467 \mathrm{~N}=11,5 \%$ erhalten, was also von 12,17 Proc. nur wenig abweicht.

Zur näheren Bestätigung (wenn diess nöthig) diente folgende Analyse:

Das alkalisch reagirende, nicht bitter schmeckende Filtrat, welches bei der oben erwähnten Cinchoninbestimmung von 0,239 Grm. Cyanwasserstoff-Cinchoninplatincyanür und bei Auswaschung des Fräcipitats mit Wasser und Lösung von kohlensaurem Natron bis keine Chlorreaction mehr wahrgenommen werden konnte, erhalten worden war, ward zur Trockne verdampft und auf die gewöhnliche Weise nach $V$ arrentrapp und Will geglüht, es gab 0,0189 Grm. $\mathrm{H}_{3} \mathrm{~N}=0,0155 \mathrm{~N}=6,48$ Proc.; nach der Berechnung hätten 6,07 Proc. gefunden werden müssen. 
Weitere Beweise für die Wahrheit des Satzes, dass das abweichende Verhalten des Cinchonins die Ursache sei von der nur theilweisen Ueberführung des Stickstoffs der Hydrocyanverbindung in Ammoniak oder analoge Basen, wurden für unnöthig erachtet.

\section{B. Saures cyanwasserstoffsaures Cincboninplatincyanür.}

Um zu bestimmen, ob es auch eine Verbindung von Cinchonin mit 2 Aeq. $\mathrm{HCy}$ und $2 \mathrm{PtCy}$ gebe, wozu Veranlassung vorhanden war in der Zusammensetzung der gleich folgenden sauren Hydrocyanate (deren Analyse vorausgegangen war) und in schon erwähnten Erscheinungen, ward schwefelsaures. Cinchonin in schwefelsäurehaltigem Wasser bei erhöhter Temperatur gelöst und Kaliumplatincyanür zugesezt. Es ent.tand sofort ein amorpher, öliger Niederschlag, der beim Erkalten gestand and nach Verlauf einiger Zeit theilweise krystallinisch ward. Versuche durch wiederholte Lösung in siedendem Wasser und Erkalten das Salz ganz krystallisiren zu lassen, missglückten bis es mir gelang diess Ziel dadurch zu erreichen, dass ich die siedende wässrige Lösung äusscrst langsam erkalten liess: die Krystalle stellten (mikroskopisch untersucht) grosse, prächtig federförmig vereinigte Parallelepepida dar.

0,35 Grm. hatten bei langsamer Erhöhung der Temperatur bis zu $195^{\circ} \mathrm{C}$. an Gewicht nichts verloren und waren vollkommen unverändert geblieben; zwischen $195^{\circ}$ und $203^{\circ}$ hatte die Zersetzung angefangen und var die Masse schwarz geworden; bei noch höherer Temperatur schmolz sie, es wurden brennbare Gase entwickelt und fand starkes Aufschwellen statt unter Zurücklassung von $0,114 \mathrm{Grm}$. Platin $=32,57$ Proc.

0,3 Grm. liessen zurück 0,095 Grm. $=31,70$ Proc., im Mittel also: 32,135 Proc. Platin; die Formel

$\mathrm{C}_{40} \mathrm{H}_{24} \mathrm{~N}_{2} \mathrm{O}_{2}, 2 \mathrm{HCy}, 2 \mathrm{PtCy}$ erfordert 32,30 Proc. Platin.

Zur Cinchoninbestimmung wurden gebraucht $0,181 \mathrm{Gr}$., erhalten bei $100^{\circ}$ getrocknetes Cinchonin 0,091 Grm. = 50,27 Proc.;

die Berechnung gibt 50,32 ",

Die Zersetzung hat nach folgender Formel stattgefunden:

$$
\begin{gathered}
\stackrel{+}{+} \text { Cinch., } \mathrm{SO}_{3}+2(\mathrm{KaCy}, \mathrm{PtCy})+2\left(\mathrm{HO}, \mathrm{SO}_{3}\right)= \\
\text { (Cinch., } 2 \mathrm{HCy}), 2 \mathrm{PtCy}+2\left(\mathrm{KaO}, \mathrm{SO}_{3}\right) .
\end{gathered}
$$

Zur Bestätigung auf synthetischem Wege wurden $0,4 \mathrm{Grm}$. bei $100^{\circ}$ getrocknetes Cinchonin in rerdünnter Schwefelsäure gelöst und bei gewöhnlicher Temperatur Kaliumplatincyanür im Ueberschusse zugesetzt und sodann erwärmt. In der sauer reagirenden Flüssigkeit 
entstand jetzt sofort ein krystallinischer Niederschlag, dessen Gewicht 0,695 Grm. betrug, während

$0,794 "$ hätten erhalten werden sollen.

0,099 "Verlust übereinstimmend mit 0,05 Grm. Cinchonin. Aus der Mutterlauge wurden durch Sodalange 0,058 Grm. bei $100^{\circ}$ getrocknetes Cinchonin gefällt.

Zur Stickstoffbestimmung unter den abgeänderten Bedingungen genommen: $0,359 \mathrm{Grm}$, welche $0,05184 \mathrm{H}_{2} \mathrm{~N}=0,0427 \mathrm{Grm} . \mathrm{N}=$ 11,90 Proc. lieferten. Die Formel erfordert 13,72 Proc.; das Deficit von 1,82 Proc. findet in dem Vorhergehenden seine Erklärung.

C. Neutrales cyanwasserstoffsaures Chininplatincyanür.

Als das Kaliumplatincyanür zu einer Lösung von salzsaurem Chinin in warmem Wasser (ohne Zusatz von Säure) zugefügt worden war, wurde ein theils öliger, theils harziger amorpher Niederschlag abgeschieden, der sich wie frisch bereiteter amorpher Schwefel zu dünnen (fluorescirenden) Fäden ausziehen liess und unter dem Mikroskope keine Spur von krystallinischer Structur zeigte, auch nicht beim Erkalten, durch welches die Verbindung hart geworden war. Es wollte mir nicht gelingen sie durch langzames $\Delta$ bkühlen siedender wässeriger und alkoholischer Lösungen zum Krystallisiren zu bringen. Beim Verdampfen des Alkohols blieb ein hellgelblicher, vollkommen durchscheinender, weicher, harziger Rückstand übrig, der durch Wasser undurchsichtig, weiss und allmählich hart wurde, ohne dass auch hier Krystallbildung wahrgenommen werden konnte.

$0,263 \mathrm{Grm}$. der lufttrockenen Verbindung verloren beim Erwärmen auf dem Wasserbade 0,01 Grm. $=3,8$ Proc., doch bei weiterem Erhitzen bis zu $150^{\circ}$ fand keine Gewichtsabnahme mehr statt. Bei letztgenannter Temperatur war die Verbindung sehr hellgelb geworden, doch war ein Verlust nicht zu bemerken.

Zwischen $150^{\circ}$ und $160^{\circ}$ schmolz sie zu einer hellbraun gefärbten Flüssigkeit and fing die Zersetzung an. Bei Verstärkung der Hitze ward die Flüssigkeit dunkelroth, beinahe schwarz, schwoll stark auf, liess brennbare Gase entweichen und liess 0,051 Grm. Platin $=$ 19,4 Proc. zurück.

Zur Bestimmung der Menge des Chinins wurden genommen 0,065 Grm. der lufttrockmen Verbindung und erhalten 0,041 Grm. $=$ 63,08 Proc. 
Diese analytischen Resultate rechtfertigen die Formel:

$\left(\mathrm{C}_{40} \mathrm{H}_{24} \mathrm{~N}_{2} \mathrm{O}_{4}, \mathrm{HCy}\right), \mathrm{PtCy}+2 \mathrm{HO}$, welche verlangt:

berechnet:

erhalten :

Wasser 3,65

3,80 Proc.

Platin 20,00

$19,40 \quad$,

Chinin 65,59

$63,08 \quad$,

Die Reaction hatte also folgendermaassen stattgefunden:

$$
\begin{gathered}
\mathrm{C}_{40} \mathrm{H}_{24} \mathrm{~N}_{2} \mathrm{O}_{4}, \mathrm{HCl}+\mathrm{KaCy}, \mathrm{PtCy}= \\
\left(\mathrm{C}_{40} \mathrm{H}_{24} \mathrm{~N}_{2} \mathrm{O}_{4}, \mathrm{HCy}\right), \mathrm{PtCy}+\mathrm{KaCl} .
\end{gathered}
$$

Zum synthetischen Beweise wurden von dem lufttrocknen Hydrochlorate $\left(\mathrm{C}_{40} \mathrm{H}_{24} \mathrm{~N}_{2} \mathrm{O}_{4}, \mathrm{HCl}+3 \mathrm{HO}\right) 0,7 \mathrm{Grm}$. in warmem Wasser gelöst und nach dem Erkalten ein geringer Ueberschuss von $\mathrm{KaCy}, \mathrm{PtCy}$ zugesetzt; der amorphe Niederschlag wurde ausgewaschen, in Alkohol gelöst und auf dem Wasserbade verdampft, er wog 0,869 Grm. Die Mutterlauge nebst Waschwasser auf ein kleines Volumen eingedampft, mit einer Lösung von kohlensaurem Natron und Aether geschüttelt, die ätherische Lösung abgeschieden und verdanpft, lieferten noch 0,03 Grm. bei $100^{\circ}$ getrocknetes Chinin $=0,044 \mathrm{Grm}$. der Verbindung. Im Ganzen also $0,869+0,044=0,913$ Grm., statt 0,860 Grm. nach der Berechnung; 0,053 Grm. waren also $\mathrm{zu}$ viel erhalten, wovon mir die Ursache unbekannt ist. Vielleicht liegt sie in dem Wassergehalt des salzsauren Chinins; wäre dieses ganz wasserfrei gewesen, so hätten $0,924 \mathrm{Grm}$. erhalten werden müssen. Eine eigene Untersuchung in dieser Beziehung ist jedoch von mir nicht angestellt worden.

$0,255 \mathrm{Grm}$. der auf dem Wasserbade getrockneten Verbindung entwickelten beim Glühen mit Natronkalk in dem abgeänderten Ofen und der mit Kupferblech umgebenen Glasröhre 0,0324 Grm. $\mathrm{H}_{3} \mathrm{~N}=$ $0,0267 \mathrm{~N}=10,47$ Proc. Die Formel verlangt 11,76 Proc.

D. Saures cyanwasserstoffsaures Chininplatincyanür.

0,149 Grm. der breiten, gestreiften, (unter dem Mikroskop) tafelförmigen Krystalle hatten sich bei mehrstündiger Erhitzung unter und auf $155^{\circ}$ an Gewicht nicht verändert; erst bei $180^{\circ}$ hatten sie ein Mgrm. verloren und bei $190^{\circ}$ entstand bei zunehmendem Gewichtsverluste eine hellgelbe Färbung, die beim Erkalten fortdauerte, so dass die Zersetzung begonnen hatte. Bei einem höhern Wärmegrad schmolz die Verbindung, sie ward dunkel, fast schwarz gefärbt und blieben 0,044 Grm. Platin $=29,53$ Proc. zurück.

Beim Wiederholen der Analyse mit 0,322 Grm. war beim Erhitzen bis zu $165^{\circ}$ keine Veränderung wahrzunehmen; bei ungefähr 
$180^{\circ}$ begann die Zersetzung und es blieben 0,1 Grm. Platin $=$ 31,06 Proc. zurück.

Zum dritten Male verbrannt lieferten 0,762 Grm. 0,235 Grm. Platin $=30,84$ Proc. Das Resultat der drei Analysen im Mittel ist also 30,48 Proc.

Zur Chininbestimmung genommen 0,235 Grm.; gefällt 0,11 Grm. und aus dem Filtrate durch kaustisches Natron und Aether abgeschieden 0,01 Grm., also $0,11+0,01=0,12$ Grm. $=51,06$ Proc.

Stellen wir als Formel auf:

$$
\begin{array}{cc}
\left(\mathrm{O}_{40} \mathrm{H}_{24} \mathrm{~N}_{2} \mathrm{O}_{4}, 2 \mathrm{HCy}\right), 2 \mathrm{PtCy} \text {, so sind } \\
\text { berechnet: } & \text { erhalten : } \\
\text { Platin } 31,53 & 30,48 \text { Proc. } \\
\text { Chinin 51,59 } & 51,06,
\end{array}
$$

Bei grosser Uebereinstimmung im Chiningehalte ist nicht zu leugnen, dass der Unterschied im Platin zu viel beträgt. Berechnet man die Menge des Metalls für die Verbindung mit 2 Aeq. HO, so ist 30,65 Proc. das Resultat, welches also von dem Gefundenen nor sehr wenig abweicht.

Wir glauben aber zu diesem Schlusse nicht berechtigt zu sein, da kein directer Beweis geliefert werden konnte; sollte er aber in der That die wahre Zusammensetzung ausdrücken, so würde aus dem Vorausgehenden folgen, dass diess Wasser sich nicht ohne Zersetzung aus dem Salze entfernen lässt.

$$
\begin{aligned}
& \mathrm{C}_{40} \mathrm{H}_{24} \mathrm{~N}_{2} \mathrm{O}_{4}, \mathrm{SO}_{3}+2(\mathrm{KaCy}, \mathrm{PtCy})+2 \mathrm{HO}+\mathrm{SO}_{3}= \\
& \left(\mathrm{C}_{40} \mathrm{H}_{24} \mathrm{~N}_{2} \mathrm{O}_{4}, 2 \mathrm{HCy}\right), 2 \mathrm{PtCy}+2\left(\mathrm{KaO}, \mathrm{SO}_{3}\right)
\end{aligned}
$$

ist die Gleichung, welche aufklärt, was bei der Wechselwirkung muthmaasslich stattfindet.

Zur Synthese genommen 0,815 Grm. Chinin, erhalten 1,554 Grm. der bei $100^{\circ}$ getrockneten Verbindung. Aus Matterlauge und Waschwasser gefällt $0,016 \mathrm{Grm}$. Chinin. Bringen wir diese von der zur Untersuchang genommenen Menge in Abzug, so jätten 1,55 Grm. erhalten werden sollen. Auch hier muss bemerkt werden, dass diess Resultat auf irgend welchen Wassergf halt der bei $100^{\circ}$ getrockneten Verbindung hinweist. Denn, welche Vorsichtsmaassregeln auch getroffen werden um Verlust möglichst zu vermeiden, so ist es doch nicht wohl möglich ihm ganz zu entgehen und hier wurden im Gegentheil $0,004 \mathrm{Grm}$. zu viel gefunden. Setzen wir wieder diesen Wassergehalt zu 2 Aeq. an, so hätten 1,539 Grm. erhalten werden müssen, was mehr Wahrscheinlichkeit hat. 
Es ist also wirklich viel Grund für die Annahme vorbanden, dass Wertheim's Formel die richtige ist.

Zwei Stickstoffbestimmungen wurden gemacht, die eine nach der gewöhnlichen, die andere nach der abgeänderten Methode;

$0,315 \mathrm{Grm}$. nach der ersten gaben $0,038 \mathrm{Grm} . \mathrm{H}_{3} \mathrm{~N}=0,0313 \mathrm{~N}$ $=9,93$ Proc.; nach der letzten entwickelten:

0,223 Grm. 0,0324 Grm, $\mathrm{H}_{3} \mathrm{~N}=0,0267$ Grm. $\mathrm{N}=11,97$ Proc.

Der Stickstoffgehalt des wasserfreien Salzes $=13,37$ Proc.; der des wasserhaltigen $=13$ Proc.

Auch hier scheint also die höhere Temperatur ron günstigem Einflusse auf die Bildung von $\mathrm{H}_{3} \mathrm{~N}$ oder dergleichen Basen gewesen zu sein.

E. Neutrales cyanwasserstoffsaures Chinidinplatincyanür.

Diese Verbinüung ward auf gleiche Weise dargestellt und zeigte rollkommen dieselben Erscheinungen und Eigenschaften wie das entsprechende Chininsalz. Auch bei diesem Körper waren die Versuche zur Krystallisation von keinem günstigeren Erfolge begleitet.

Zur Wasser- und Platinbestimmung wurden abgewogen 0,289 Grm. in lufttrockenem Zustande, welche unter $100^{\circ} 0,114$ Grm. $=4,84$ Proc. verloren. Bei weiterer Erhitzung blieb die Substanz unverändert ohne Gewichtsabnahme zu erleiden bis zu $170^{\circ}$. Zwischen $170^{\circ}$ und $190^{\circ}$ begann die Zersetzung; 0,055 Grm. Platin blieben zurïck $=19$ Proc. Für die Chinidinbestimmung genommen von dem lufttrocknen Salze 0,178 Grm. und gefällt $0,115 \mathrm{Grm} .=64,61$ Proc.

\begin{tabular}{lrrr}
\multicolumn{2}{l}{ Also erhalten : } & \multicolumn{2}{c}{ berechnet: } \\
Wasser & 4,84 & 5,36 & Proc. \\
Platin & 19,00 & $19,68 \quad "$ \\
Chinidin & 64,61 & $64,41 \quad "$
\end{tabular}

Die Berechnung geschah nach der Formel: $\left(\mathrm{C}_{40} \mathrm{H}_{24} \mathrm{X}_{2} \mathrm{O}_{4} \mathrm{HCy}\right)$, PtCy +3 HO, die, wenn auch nicht vollkommen, doch so sehr mit den analytischen Resultaten übereinstimmt, dass ich glaubte sie für die wahre balten zu dürfen.

Zum Ueberflusse wurden $0,7 \mathrm{Grm}$. salzsaures Chinidin in lufttrockenem Zustande $\left(\mathrm{C}_{40} \mathrm{H}_{24} \mathrm{~N}_{2} \mathrm{O}_{4}, \mathrm{HCl}+2 \mathrm{HO}\right)$ durch Kaliumplatincyanür zersetzt; $0,839 \mathrm{Grm}$. Niederschlag bei $100^{\circ}$ getrocknet und 0,028 Grm. Chinidin, aus der Mutterlange niedergeschlagen und durch Lösung von kohlensaurem Natron und Aether gelöst, wurden statt der berechneten Menge von 0,880 Grm. der Hydiocyanverbindung erhalten; 
also 0,041 Grm. Verlust $=0,0279$ Grm. Chinidin. Ein genaueres Resultat kon.te wohl nicht verlangt werden.

Zur Stickstoffbestimmung in der abgeänderten Röbre nebst Ofen genommen $0,348 \mathrm{Grm}$. auf einem Wasserbade getrocknet; erhalten 0,00216 Grm. $\mathrm{H}_{3} \mathrm{~N}=0,00178 \mathrm{~N}=0,511$ Proc., während die $\mathrm{Zu}$ sammensetzung erfordert 11,76 Proc. N. Die Bestimmung ward wegen der grossen Differenz mit 0,125 Grm. wiederholt; erhalten 0,00081 Grm. $\mathrm{H}_{3} \mathrm{~N}=0,00067 \mathrm{~N}=0,536$ Proc.

Diess Resultat stimmt also mit dem vorigen uberein und ist nicht günstiger. Welche Folgerung ist aus diesem unerwarteten Resultate zu ziehen? Unseres Erachtens die, dass die Constitution dieser Hydrocyanplatinverbindung eine andere sein muss; welche? Wir wagen es nicht einmal uns auf das endlose Gebiet der Vermuthungen zu begeben, und werden also noch weniger einen bestimmten Ausspruch thun; die Daten dazu fehlen gänzlich. - Die Thatsache selbst ist bemerkenswerth und ist für ein abweichendes Verhalten der Verbindung gegen Natronkalk bei erhöhter Temperatur beweisend.

F. Saures cyanwasserstoffsaures Chinidinplatincyanür.

$1,587 \mathrm{Grm}$, verloren im Luftbade unter $120^{\circ} \mathrm{C} .0,106 \mathrm{Grm}$. $=6,68$ Proc.; beim Erhitzen von $120^{\circ}-150^{\circ}$ wurde kein Wasser mehr verjagt. Ein höherer Wärmegrad von $150^{\circ}-170^{\circ}$ bewirkte die Zersetzung.

0,455 Grm. Platin $=28,67$ Proc. blieben zurück, die jedoch eine Spur Eisen enthielten, so dass die Verbrennung wiederholt ward:

1) mit 0,231 Grm., welche 0,067 Grm. Pt $=29$ Proc. und

2) mit 0,315 Grm., welche 0,094 Grm. Pt $=29,8$ Proc. hinterliessen.

Das Mittel aus den beiden letzten Bestimmungen ist $=29,4$ Proc.

Für die Chinidinbestimmung genommen: von der bei $120^{\circ}$ getrockneten Verbindung $0,58 \mathrm{Grm}$., welche lieferten $0,285 \mathrm{Grm}$. $=$ 49,14 Proc. (auf das wasserfreie Salz bezogen) $=45,86$ Proc. für das krystallisirte Salz; ausserdem wurden noch durch Aether ausgezogen 0,007 Grm. $=1,2$ Proc. oder 1,11 Proc. für das kryst. Salz; also im Ganzen 50,34. Proc. oder 46,97 Proc.

Nach der Formel: $\mathrm{C}_{40} \mathrm{H}_{24} \mathrm{~N}_{2} \mathrm{O}_{4}, 2 \mathrm{HCy}, 2 \mathrm{PtCy}+5 \mathrm{HO}$

berechnet:

Wasser $\quad 6,68$

Platin $\quad 29,42$

Chinidin 49,14 erhalten:

6,68 Proc.

29,40

46,97 " 
Zur Controle auf synthetischem. Wege genommen von dem bei $100^{\circ}$ getrockneten Chinidin $1,415 \mathrm{Grm}$.; erhalten aus der Matterlange also $\begin{array}{cl}0,006, \quad \text { Chinidin, } \\ 1,409, \quad \text { zu berechnen, welche } 2,746 \mathrm{Grm} \text {. }\end{array}$ bei $100^{\circ}$ getrocknet gaben, statt 2,731 Grm., also 0,015 Grm. zu viel, was der Temperatur, bei welcher getrocknet ward, zugeschrieben werden muss; ein Wärmegrad von $100^{\circ}$ ist zum vollkommenen Austrocknen nicht zureichend; Spuren von Wasser waren also noch vorhanden.

Stickstoffbestimmung :

0,332 Grm. in einer mit Kupferblech umwickelten Röhre, aber in dem gewöhnlichen Ofen erhitzt, lieferten 0,02484 Grm. $\mathrm{H}_{3} \mathrm{~N}=$ $0,02045 \mathrm{~N}=6,159$ Proc., obgleich aie Formel 12,48 Proc. verlangt.

Bei Wiederholung der Stickstoffbestimmung wurde von 0,302 Grm. ausgegangen und sowohl in der abgeänderten Röhre als in dem abgeänderten ofen ungefähr 2 Stunden lang erhitzt; es wurden frei $0,04212 \mathrm{H}_{3} \mathrm{~N}=0,03468 \mathrm{~N}=11,48$ Proc.; die höhere Temperatur und das andauernde Erhitzen waren hier von günstiger Wirkung.

G. Neutrales cyanwasserstoffsaures Cinchonidinplatincyanür.

Die Darstellung geschah übereinstimmend mit den analogen Chininund Chinidinverbindungen; statt des Hydrochlorats ward jedoch schwefelsaures Cinchonidin angewandt. Auch dem Ansehen nach war die Verbindung von den beiden genannten Doppelsalzen nicht zu unterscheiden, sie schmolz auf dem Wasserbade zu einer hellgelb gefärbten durchscheinenden Flüssigkeit nur bei Gegenwart von Wasser; im trocknen Zustande fand diess Schmolzen nicht statt. Da nur eine kleine Menge zur Verfügung stand, so wurde nur der Platingehalt von $0,122 \mathrm{Grm}$. bei $100^{\circ}$ getrocknet bestimmt; erhalten: 0,024 Grm. Platin $=19,67$ Proc.

Die Formel $\mathrm{C}_{40} \mathrm{H}_{24} \mathrm{~N}_{2} \mathrm{O}_{2}, \mathrm{HCy}, \mathrm{PtCy}$ erfordert 21,52 Proc.; also Verlust $=1,85$ Proc., was vielleicht einem Wassergehalt zuzuschreiben ist, der bei $100^{\circ}$ nicht verjagt wurde.

Sie zeigtc beim Erhitzen dieselben Erscheinungen wie die übrigen Hydrocyanverbindungen und war in Alkohol löslich, in Aether nicht merklich. Die wässerige Lösung hatte einen stark bittern Geschmack.

H. Saures cyanwasserstoffsaures Cinchonidinplatincyanür.

$0,226 \mathrm{Grm}$. verloren bis zu $120^{\circ} \mathrm{C}$. erhitzt $0,0145 \mathrm{Grm} .=$ 6,41 Proc. Wasser; bei $140^{\circ}$ ungefähr fing die Verbindung an hellgelb zu werden und sich zu zersetzen; 0,068 Grm. Platin $=30,09$ Proc. blieben zurück. 
Zum zweiten Male genommen 0,381 Grm., welche 0,115 Grm. Platin $=30,18$ Proc. lieferten.

Das Mittel der beiden Versuche ist $=30,135$ Proc.

Zur Cinchonidinbestimmung genommen 0,356 Grm., gefällt 0,162 Grm. $=45,51$ Proc.

Diese Resultate führen anf die Formel:

\begin{tabular}{|c|c|c|}
\hline \multicolumn{3}{|c|}{$\left(\mathrm{C}_{40} \mathrm{H}_{24} \mathrm{~N}_{2} \mathrm{O}_{2}, 2 \mathrm{HCy}\right), 2 \mathrm{PtCy}+5 \mathrm{HO}$} \\
\hline $\begin{array}{c}\text { berech } \\
\text { Wasser }\end{array}$ & et: & \\
\hline Platin & 30,137 & 30,135 \\
\hline Cinchonidin & 46,880 & 45.510 \\
\hline
\end{tabular}

Die Synthese gab folgendes Resultat: von $0,607 \mathrm{Grm}$. bei $100^{\circ}$ getrocknetem schwefelsaurem Cinchonidin wurden erhalten 0,99 Grm., bei $100^{\circ}$ getrocknetes Hydrocyanat und $0,025 \mathrm{Grm}$. Cinchonidin aus Mutterlauge und Waschwasser niedergeschlagen.

$0,607 \mathrm{Grm}$ schwefelsauren Cinchonilins $\left(\mathrm{C}_{40} \mathrm{H}_{24} \mathrm{~N}_{2} \mathrm{O}_{2}, \mathrm{SO}_{3}, \mathrm{HO}\right)$ entsprechen 0,523 Grm. Cinchonidin;

hiervon abgezogen $0,025, ", \quad$,

welche $0,989 \mathrm{Grm}$. der wasserfreien Verbindung hätten liefern müssen. Es waren also statt irgend eines unvermeidlichen Verlustes 0,001 Grm. zuviel erhalten, was vermuthlich in dem Umstande seine Erklärung findet, dass das Trocknen nicht bei $120^{\circ}$, sondern auf dem Wasserbade stattfand, so dass nicht alles Krystallwasser verjagt wurde. Die chemische Umsetzung zwische ${ }_{22}$ schwefelsaurem Cinchonidin und Kaliumplatincyanür kann also durch folgende Gleichung dargestellt werden:

$$
\begin{aligned}
& \mathrm{C}_{40} \mathrm{H}_{24} \mathrm{~N}_{2} \mathrm{O}_{2}, \mathrm{SO}_{3}+2(\mathrm{KaCy}, \mathrm{PtCy})+2 \mathrm{HO}, \mathrm{SO}_{3} \\
& =\left(\mathrm{C}_{40} \mathrm{H}_{24} \mathrm{~N}_{2} \mathrm{O}_{2}, 2 \mathrm{HCy}\right), 2 \mathrm{PtCy}+2\left(\mathrm{KaO}, \mathrm{SO}_{3}\right) .
\end{aligned}
$$

Stickstoff bestimmung :

0,277 Grm. des krystallisirten, wasserhaltigen Salzes entwickelten in dem gewöhnlichen Ofen, doch in mit Kupferblech umwickelter Röhre, 0,03996 Grm. $\mathrm{H}_{3} \mathrm{~N}=0,0329 \mathrm{~N}=11,9$ Proc.; die Formel verlangt 12,78 Proc., so dass die Ammoniakbildung unter diesen Umständen ziemlich vollständig stattyefunden hatte.

Löslichkeit der Hydrocyanplatinverbindungen.

Die Löslichkeit der verschiedenen Hydrocyanplatinverbindungen in den gebräuchlichsten Lösungsmittelr Wasser, Alkohol und Aether, ward hauptsächlich in der Absicht bestimmt, wo möglich auf diesem Wege eine Trennung der Chinaalkaloide zu bewirken. 
Wie einfach diese Bestimmung auch scheinen möge, so hat sie mir doch viele Schwierigkeit und duch Wiederholung der Versuche wegen Misslingens grossen Zeitverlust verursacht. Vollkommen muss ich bestätigen, was Professor G. J. Mulder*) bemerkt hat, dass man nach den verschiedenen Methoden auch andro Resultate erhält, und dass, wenn die Art wie eine Salzlösung erbalten wurde nicht genau beschrieben ist, man auch an den Resultaten nichts hat. Wiederholt ergab sich mir auch die Nothwendigkeit den Gebrauch der Filter möglichst zu vermeiden, da diese durch Einsaugen und Flächenwirlzung, namentlich bei schwer Iöslichen Körpern, zu groben Fehleru Veranlassung geben können. Meine Versuche können nur für die Fälle wo es gilt die Löslichkeit bei gewöhnlicher Temperatur zu bestimmen auf Genauigkeit Ansprach machen, haben aber hinsichtlich der Löslichkeit in den kochenden Flüssigkeiten nur einen annälernden Werth.

M ulder's Angaben und Vorschriften gemäss (namentlich um Uebersättigung zn vermeiden) ward ein Ueberschuss des Salzes in einer Stöpselflasche bei langsam steigender Temperatur in der Zeit zwischen etwa $9 \mathrm{Uhr}$ Morgens und etwa $2 \mathrm{Uhr}$ Nachmittags wiederholt mit dem Lösungsmittel durcheinander geschüttelt; sodann die Mischung zum Absitzen so lange in Ruhe gelassen, bis die obenstehende Flüssigkeit vollkommen hell geworden war (was oft geraume Zeit erforderte), and dann wicder bei langsam steigender Luftemperatur 50 CC. mit einer Pipette entfernt und verdampft. Sobald diese $50 \mathrm{CC}$. abgesondert waren, wurde die Temperatur der Lösıiıg in der Flasche bestimmt.

Um die im Allgemeinen weit grössere Lösliclikeit der Verbindungen in den kochenden Lösungsmitteln ungefähr kennen zu Iernen, ward entweder ein Ueberschuss des Salzes mit dem Lösungsmittel eine Zeit lang gekocht, durch einen Wasserbadtrichter so heiss als möglich filtrirt, und entweder in einem Messglase $50 \mathrm{CC}$. aufgefangen and verdampft, wie es mit der ätherischen Flüssigkeit geschah, oder das auf dem Filter Zurückbleibende gewogen und das Volumen des Filtrats bestimmt, wie es bei den alkoholischen und wässerigen Lösungen stattfand; oder es wurde eine bestimmte Menge abgewogen und gesehen wie viel von dem in einer Bürette vorhandenen Lösungsmittel zur Lösung bei Siedehitze nöthig war. Das erste Verfahren wurde bei den sauern, das zweite bei den neutralen Verbindungen befolgt.

Obgleich beide Methoden mangelhaft sind, so wusste ich sie doch nicht durch bessere zu ersetzen. Dass die untenstehenden Resultate jedoch von der Wahrheit nicht weit entfernt sind, hat sich mir mehr-

*) Scheikundige verhandelingen en onderzoekingen Thl. III. Heft ?. p. 21. 
mals durch Anwendung beider Methoden ergeben; sicherlich entsprechen sie dem beabsichtigten Zwecke, da keide Classen von Verbindungen unter denselben und möglichst übereinstimmenden Bedingungen untersucht wurden.

\section{Löslichkeit:}

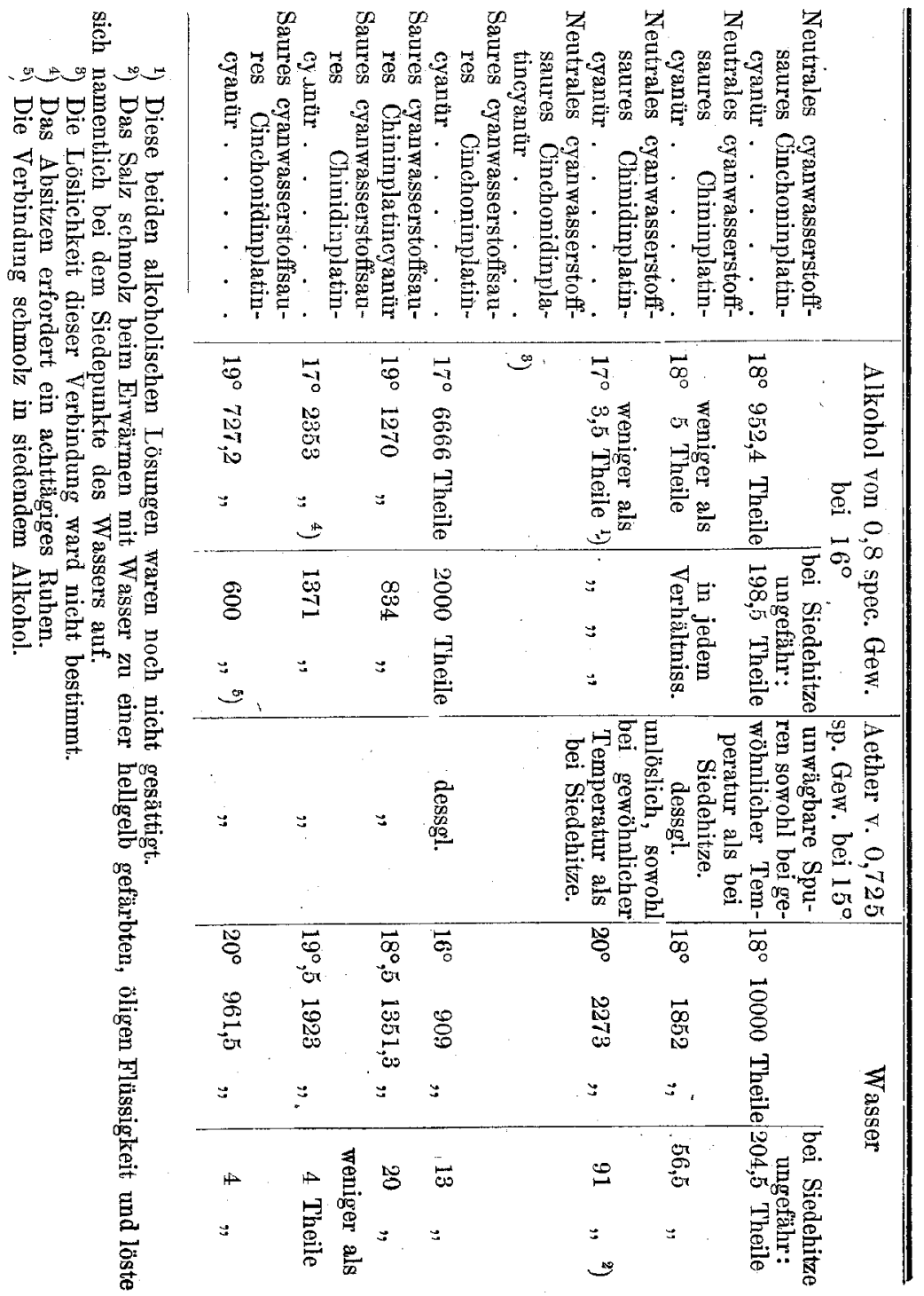


Die Lösungen der beiden Cinchoninsalze in kaltem Wasser und Alkohol hatten eine neutrale Reaction, fluorescirten nicht, auch nicht nach Zusatz von Schwefelsäure und bewirkten mit salpetersaurem Silberoxyd ein Opalisiren; die in Wasser ward durch kohlensaures Natron noch schwach und durch Kaliumquecksilberjodid ziemlich stark getruibt.

Die bei gewöhnlicher Temperatur bereiteten wässerigen Lösungen der neutralen Chinin- und Chinidinverbindungen hatten einen bittern Geschmack, fluorescirten erst nach Zusatz von Schwefelsäure und zeigten ausser der Reaction mit kaustischem Natron, salpetersaurem Silberoxyd und Kaliumquecksilberjodid auch die grüne Färbung mit Chlorwasser und Ammon; die Lösung des sauern Chinidinsalzes hatte keinen bittern Geschmack und gab mit Chlorwasser und Ammon, sowie auch mit salpetersaurem Silberoxyd nur eine geringe Reaction; sie fluorescirte schon ohne Zusatz von Schwefelsäure und ward durch kohlensaures Natron nicht gefällt, wohl aber durch Kaliumquecksilberjodid.

Die wässerige Lösung von saurem cyanwasserstoffsaurem Chininplatincyanür war davon verschieden durch den Besitz eines bittern Geschmacks, das deutlichere Hervorbringen der Reaction mit Chlor und Ammoniak und das schwache Trübwerden durch kaustisches Natron.

Die Lösung des sauren Cinchonidinsalzes in Wasser hatte einen bittern Geschmack und fluorescirte nicht, auch nicht nach Zusatz von Schwefelsäure; sie brachte sowohl mit salpetersaurem Silberoxyd als mit Natronhydrat ein schwaches Opalisiren, mit Kaliumquecksilberjodid aber eine starke Trübung hervor.

Sämmtliche Lösungen der sauren Salze in siedendem Wasser hatten eine stark saure Reaction; die der neutralen, auch die in Alkohol, reagiften neutral.

Betrachten wir obenstehende Tabelle, so ergibt sich uns:

1) dass von den neutralen Verbindungen das cyanwasserstoffsaure Cinchoninplatincyanür sich namentlich durch Schwerlöslicbkeit in Wasser und Alkohol auszeichnet, und hinsichtlich des Verhaltens zu letzterer Flüssigkeit ron der entsprechenden Chinin- und Chinidinverbindung sehr verschieden ist;

2) dass die sauren Salze bei gewöhnlicher Temperatur in Wasser und Alkohol sehr schwer löslich sind, doch ziemlich leicht, namentlich das cyanwasserstoffsaure Chinidinplatincyanür und die entsprechende Cinchonidinverbindung, beim Kochen mit Wasser.

Die sauren Salze wurden in grösserer Menge in Wasser bei Zusatz von verdünnter Schwefelsäure gelöst; die neutralen wurden hierdurch zersetzt und in saure krystallinische Verbindungen übergeführt. 
Das neutrale cyanwasserstoffsaure Cinchoninplatincyanür löste sich anfangs unverändert auf, bald aber schied sich ein harziger Körper $a b$, der später ganz krystallinisch ward, und sich als das saure Salz ergab.

Ich glaubte eine günstige Frwartung davon hegen zu dürfen, wenn ich zur Trennung der Chinabasen von der verschiedenen Löslichkeit dieser Doppelverbindungen Gebrauch machte. Denn wenn die Alkaloide in die neutralen Platinhydrocyanate verwandelt worden waren, so würde durch Alkohol bei gewöhnlicher Temperatur die Cinchonin- von der Chinin- and Chinidinverbindung, und diese vielleicht durch Zersetzung und Ueberführung in die Hydrojodate getrennt werden können. Diese Vermuthung ward aber durch die Erfahrung nicht bestätigt.

1. Die sämmtlichen auf S. 291 erhaltenen Alkaloide wurden durch verdünnte Salzsäure in die entsprechenden Hydrochlorate umgesetzt, und, aber mit negativem Resultate, eine Trennung durch Kaliumplatincyanür versucht.

2. $\mathrm{Zn}$ demselben $\mathrm{Zwecke}$ wurden:

$\begin{array}{cccc}0,1 & \text { Grm. } & \text { salzsauren Cinchonins } \\ 0,3 & " & " & \text { Chinins mit Krystallwasser } \\ 0,5 & " & \# & \text { Chinidins, , , }\end{array}$

in warmem Wasser gelöst und $0,53 \mathrm{Grm}$. krystallisirten Kaliumplatincyanürs (die äquivalente Menge mit etwas im Ueberschuss) zugesetzt. Alle Chinabasen waren jetzt gefällt. Bei dem Ausziehen dieses Niederschlags mit Alkohol von 0,8 spec. Gew. ergab sich jedoch, dass durch die Gegenwart der übrigen Verbindungen die Löslichkeit des cyanwasserstoffsauren Cinchoninplatincyanürs abgeändert worden sein musste, wenigstens löste sich schon durch eine relativ geringe Menge Alles auf.

Trennung auf dem vermeintlichen Wege ist also nicht möglich.

V. Stickstoffbestimmung nach Varrentrapp and Will.

Das abweichende Verhalten der Hydrocyanplatinverbindungen der Chinabasen und des Cinchonins bei der Stickstoffbestimmung nach Varrentrapp und Will gab Veranlassung auch die übrigen Alkaloide der Chinarinde in dieser Hinsicht zu untersuchen. Bevor ich das Resultat dieser Untersuchung mittheile, muss ich bemerken, dass das gebildete Ammoniak in einer titrirten Säure aufgefangen wurde, deren Stärke nach beendigtem Versuche bestimmt ward. 
Chinin.

1. 0,527 Grm. bei $125^{\circ}$ getrocknet und auf die gewöhnliche Weise mit Natronkalk verbrannt gaben $0,00378 \mathrm{Grm} . \mathrm{H}_{8} \mathrm{~N}=0,00311 \mathrm{~N}$ $=0,59$ Proc. statt 8,64. Proc. nach der Formel $\mathrm{C}_{40} \mathrm{H}_{24} \mathrm{~N}_{2} \mathrm{O}_{4}$.

2. 0,435 Grm. auf gleiche Weise behandelt hatten $0,01242 \mathrm{H}_{3} \mathrm{~N}$ $=0,01022 \mathrm{~N}=2,35$ Proc. erzeugt.

3. $0,432 \mathrm{Grm}$. bei $125^{\circ}$ getrocknet and in einer Porzellanröhre erhitzt, lieferten 0,00486 Grm. $\mathrm{H}_{3} \mathrm{~N}=0,004002 \mathrm{~N}=0,926$ Proe.

4. 0,371 Grm. in mit Kupferblech umgebener Röhre und in dem abgeänderten Ofen (S. 310) erhitzt, entwickelten $0,02268 \mathrm{H}_{3} \mathrm{~N}$ $=0,0187 \mathrm{~N}=5,04$ Proc.

5. 0,409 Grm. auf gleiche Weise $1^{1 / 2}$ Stunden lang stark geglüht gaben $0,01728 \mathrm{Grm}, \mathrm{H}_{3} \mathrm{~N}=0,01423 \mathrm{~N}=3,48$ Proc.

Es waren also erhalten worden:

$$
\begin{array}{lll}
0,59 & \text { Proc. } & \mathrm{N} \\
2,35 \quad " \quad & " \\
0,926 " & " \\
5,04 \quad " & " \\
3,48 \quad " & "
\end{array}
$$

Es zeigt sich daher, dass die Resultate sehr verschieden sind und in keinem der Fälle ailer Stickstoff in $\mathrm{H}_{3} \mathrm{~N}$ oder mit $\mathrm{H}_{3} \mathrm{~N}$ äquivalente Basen verwandelt wurde. Versuch 4 weist darauf hin, dass dazu eine höhere Temperatur nöthig ist; Versuch 5 zejgt, dass bei sehr hohem Wärmegrade wieder Zersetzung der Körper erfolgt, die sich wie $\mathrm{H}_{3} \mathrm{~N}$ verhielten.

Um so bemerkenswerther ist diese Thatsache, weil die neutrale Hydrocyanplatinverbindung des Chinins unter ungefähr denselben Bedingungen wie in Versuch 4 eine Menge $\mathrm{N}$ lieferte, welche für eine vollständigere Zerlegung des Chinins, vielleicht unter dem Einflusse des fein zertheilten Platins, zeugt.

\section{Chinidin.}

1. Gebraucht $0,683 \mathrm{Grm}$, bei $100^{\circ}$ getrocknet, für das gewöhnliche Verfahren; erhalten $0,0054 \mathrm{Grm} . \mathrm{H}_{3} \mathrm{~N}=0,00445 \mathrm{~N}=0,651$ Proc.; die Berechnung gibt 8,64 Proc.

2. 0,505 Grm, auf gleiche Weise behandelt gaben $0,01134 \mathrm{H}_{3} \mathrm{~N}$ $=0,00934 \mathrm{~N}=1,85$ Proc.

3. 0,34 Grm. in abgeänderter Röhre nebst Ofen der Behandlung 
unterworfen, entwickelten 0,03132 Grm. $\mathrm{H}_{3} \mathrm{~N}=0,02579 \mathrm{~N}=7,585$ Proc.; nsereu Resultate sind also:

$$
\begin{array}{lll}
0,651 & \text { Proc. N } \\
1,850 \quad " & " \\
7,585 & "
\end{array}
$$

Auch hier konnte also nicht aller Stickstoff in Ammoniak verwandelt werden, und war die Menge bei höherer Temperatur grösser.

Cinchonidin,

1. 0,675 Grm. bei $100^{\circ}$ getrocknet ergaben $0,01296 \mathrm{Grm} . \mathrm{H}_{3} \mathrm{~N}$ $=0,01067 \mathrm{~N}=1,58$ Proc. statt 9,09 Proc.

2. $0,293 \mathrm{Grm}$. bei $100^{\circ}$ getrocknet und mit Natronkalk erhitzt in einer mit Kupferblech umgebenen Röhre unter Anwendung des gewöhnlichen Ofens, lieferten: 0,02754 Grm. $\mathrm{H}_{3} \mathrm{~N}=0,02268 \mathrm{Grm}$. $\mathrm{N}=7,74$ Proc.

3. $0,275 \mathrm{Grm}$. getrocknet bei $100^{\circ}$ entwickelten in abgeändertem Ofen nebst Röbre eine gute Stunde lang möglichst stark erhitzt 0,01242 Grm. $\mathrm{H}_{3} \mathrm{~N}=0,01022$ Grm. $\mathrm{N}=3,71$ Proc.

Also: 1,58 Proc. $\mathrm{N}$

$\begin{array}{lll}7,74 & \prime \prime & ,\end{array}$

Hier ist also Uebereinstimmnng mit dem Chinin vorhanden; ein höherer Wärmegrad hatte die Zerlegung befördert; bei noch stärkerer Hitze aber hatte wieder Umsetzung der sich wie $\mathrm{H}_{3} \mathrm{~N}$ verhaltenden Körper stattgefunden.

\section{Cinchönin.}

Die auf Seite 309 und 310 mitgetheilten Resultate waren:

$$
\begin{aligned}
& \text { 4,00 Proc. } N \\
& 4,93, ", \\
& 1,40 " \text { (Porzellanröhre.) } \\
& 5,65, " \text { (abgeänderte Glasröbre.) } \\
& 8,24 \quad " \quad \text { ( } " \text { Röhre nebst Ofen.) }
\end{aligned}
$$

Die Zusammensetzung verlangt 9,09 Proc. $\mathrm{N}$.

Je mehr also die Temperatur in der Glasröhre gesteigert worden war, um so mehr $\mathrm{N}$ wurde erhalten.

Die Versuche haben also gelehrt:

1. dass die gewöhnliche Methode zur Stickstoffbestimmung von Varrentrapp und Will auf die Chinabasen nicht angewandt werden kann; 
2. dass eine höhere Temperatur die Bildung von Ammoniak oder analogen Körpern befördert; und

3. dass bei Chinin und Cinchonidin durch eine sehr starke Hitze wieder Zersetzung der flüchtigen Basen erfolgte.

Obschon die beim Chinidin und Cinchonin erhaltenen Resultate schon deutlich den Beweis lieferten, dass hier an keine Zersetzung des Ammoniaks in Folge der hohen Temperatur gedacht werden konnte, so wurden doch noch zum Ueberflusse

1. 0,212 Grm. $\mathrm{H}_{4} \mathrm{NCl}$ in der abgeänderten Röhre nebst Ofen gegläht; erhalten : $0,06588 \mathrm{Grm} . \mathrm{H}_{3} \mathrm{~N}=0,05425$ Grm. $=25,59$ Proc., statt 26,17 Proc.; der Verlust betrug also nur 0,58 Proc.

2. Zum zweiten Male geschah die $\mathrm{N}$ Bestimmung in dem abgeänderten Apparate mit $0,112 \mathrm{Grm} . \mathrm{H}_{4} \mathrm{NCl}$, doch wurde diessmal eine sehr lange Lage Natronkalk angewandt und die Temperatur so hoch wie möglich gesteigert, so dass die Bedingungen für die Zersetzung nicht günstiger sein konnten; entwickelt 0,03348 Grm. $\mathrm{H}_{3} \mathrm{~N}=$ 0,02757 Grm. $\mathrm{N}=24,61$ Proc.; Verlust $=1,56$ Proc. In der That hatte sich also unter den gegebenen Bedingungen etwas $\mathrm{H}_{3} \mathrm{~N}$ zersetzt, aber doch nur eine solche Menge, dass hierdurch keineswegs die Resultate der Chinin- und Cinchonidinuntersuchung erklärt werden würden.

3. Ueberdiess wurde der $N$ in $0,829 \mathrm{Grm}$. Ammoniumplatinchlorid bestimmt so viel wie möglich unter Verhältnissen, die mit den unter dem 5. Versuche beim Chinin und unter dem 3. beim Cinchonin angegebenen übereinstimmten.

Erialten 0,05778 Grm. $\mathrm{H}_{8} \mathrm{~N}=0,04758$ Grm. $\mathrm{N}=5,74$ Proc. Die Formel $\mathrm{H}_{4} \mathrm{NCl}, \mathrm{PtCl}_{2}$ erfordert 6,26 Proc. N; Verlust 0,52 Proc.

4. Zum Schlusse wurden wie beim dritten Versuche 0,29 Grm. wasserfreies gelbes Blutlaugensalz verbrannt; erhalten : 0,0756 Grm. $\mathrm{H}_{3} \mathrm{~N}$ $=0,06226 \mathrm{Grm} . \mathrm{N}=21,47$ Proc.; nach der Berechnung beträgt der Stickstoffgehalt 22,8 Proc.; also 1,33 Proc. Verlust, übereinstimmend mit dem Resultate des zweiten Versuchs*).

*) Bei der Stickstoffbestimmung in 0,209 Grm. wasserfreien Blutlaugensalzes auf dem gewöhnlichen Wege wurden frei $0,03186 \mathrm{Grm} . \mathrm{H}_{3} \mathrm{~N}=0,02624 \mathrm{Grm}$. $\mathrm{N}$ $=12,55$ Proc., worans folgt, dass auf diese Weise die Verbrennung sehr unvollkommen stattgefunden hatte und zur vollständigen Ammoniakbildung ein höherer Wärmegrad erfordert wird. (In meinem Laboratorium dient die $\mathrm{N}$ bestimmung im Ferrocyankalium schon seit Jahren als Uebungsaufgabe. Frfahrungen wie die des Verfassers sind aber dabei nie gemacht worden, die Resultate waren vielmehr bei richtiger Arbeit stets ganz befriedigend. Der Herausgeber). 
Im Centralblatte 1861 p. 44 theilt $\mathrm{Knop}$ die Abänderung mit, welche E. Mulder binsichtlich der Stickstoffbestimmung nach der Methode von Will und Varrentrapp empfohlen hat *), und bemerkt in dieser Beziehung, dass es nicht rathsam sei eine lange Colonne Natronkalk anzuwenden, weil das Ammoniak dann Gefahr laufe sich in Wasserstoff und Stickstoff zu zersetzen, wie sich aus Folgendem von dem Verfasser angestellten Versuche ergibt.

Ein Verbrennungsrohr ward mit Natronkalk gefüllt, sowie es beim Verbrennen geschieht, und die Menge desselben gewogen. Das Rohr wurde dann unter Wasser umgekehrt und das Luftvolum, das nun daraus austrat, aufgefangen und gemessen. Dann wurde dieselbe Menge Natronkalk mit 2 Grm. Platinsalmiak gemengt und wie bei der Stickstoffbestimmung die Verbrennung bewerkstelligt; es lag eine nicht ungewöhnlich lange Colonne Natronkalk vor. Die entwickelten Dämpfe gingen durch ein enges U-förmiges Rohr in ein auf den einen Schenkel aufgesetztes graduirtes Rohr, das mit salzsaurem Wasser nicht ganz gefüllt war. Die in dem graduirten Rohre angesammelte Luft ward mit dem salzsauren Wasser geschüttelt, während man das Verbrennungsrohr vollständig erkalten liess, wobei das Gas aus dem graduirten Rohre in das Verbrennungsrohr zurücktrat.

„Man findet nun (sagt Knop) im graduirten Rohre einen Ueberschuss von Gas, der bei 2 Grm. Platinsalmiak 15-20 CC. betrug und der bei dem geringen Inhalte an Luft, den das Verbrennungsrohr vor der Verbrennung enthielt, nicht (?) den geringen Fehlern der verschiedenen Ausdehnung vor und nach dem Versuche zugeschrieben werden konnte, ein Beweis (!), dass dabei eine gewisse Menge Ammoniak wirklich in Wasserstoff und Stickgas zerlegt worden ist."

„Diese Zersetzung wird gewiss überall eintreten, wo die Colonne Natronkalk, die man der Mischung desselben mit der zu verbrennenden Substanz noch vorlegt, sehr lang und zugleich zu stark erhitzt ist, und es kann hieraus jedenfalls (!) ein Fehler entspringen, der grösser ist als diejenigen, welche man durch andere Mittel mainutiös zu vermeiden sucht. Immer aber ist auch dieser Fehler sehr klein, und es wird wohl selten (!) bei bestimmten chemischen Verbindungen die Natronkalkmethode etwas zu wünschen übrig lassen."

*) Scheikundige verhandelingen en onderzoekingen, door G. J. Mulder Th. 3, 1. Heft p. 26. 
Unserer Ansicht nach hätte $\mathrm{Knop}$ um seinen Versuch als Beweis für die Zerlegung des Ammoniaks in Wasserstoff und Stickstoff gelten zu lassen, denselben Versuch ohne Gegenwart von Platinsalmiak machen, wenigstens bestimmen müssen, dass die 15 bis $20 \mathrm{CC}$. Gas wirklich aus Wasserstoff und Stickstoff bestanden.

Hiervon ergibt sich aus Knop's Mittheilungen nichts, oder vielmehr es ergibt sich daraus, dass das Gas einer näheren Untersuchung nicht unterworfen wurde; ohne dass dafür ein ausreichender Grund angeführt würde, wird nur auf die Anwesenheit beider geschlossen, und angenommen, dass die Umstände, unter welchen der Versuch vorgenommen wurde, wohl nicht als Ursache der Erscheinung betrachtet werden können.

Wir glauben denn auch nicht, dass das Ammoniak bei der Temperatur zersetzt wird, bei welcher die Stickstoffbestimmung gewöhnlich stattfindet, wie es aus den von uns angestellten Bestimmungen hervorgeht, und dass diess nur bei einer geringen Menge geschieht, wenn die Temperatur in dem abgeänderten Ofen und in mit Kupferblech umwickelter Röhre bedeutend höher gesteigert ist.

Die Formeln aller Chinabasen sind hinsichtlich ihres Stickstoffgehaltes auf die Bestimmung dieses Elements in dem gasförmigen $\mathrm{Zu}$ stande basirt, und weder V arrentrapp and Will noch irgend ein andrer Chemiker hat, so weit uns bekannt ist, ihre Methode an diesen Alkaloiden erprobt. Es kann also nicht befremden, dass die angegebene Thatsache nicht schon früher constatirt worden ist. Wir fanden darin hinreichende Veranlassung die Methode auch an anderen Basen von hekannter Zusammensetzung zu prüfen.

\section{Brucin.}

$0,361 \mathrm{Grm}$. bei $120^{\circ}$ bis $130^{\circ}$ getrocknet und auf die gewöhnliche Weise verbrant, lieferten 0,02808 Grm. $\mathrm{H}_{3} \mathrm{~N}=0,02312 \mathrm{~N}=$ 6,4 Proc., während die Formel $\mathrm{C}_{46} \mathrm{H}_{26} \mathrm{~N}_{2} \mathrm{O}_{3}, 7,05$ Proc. erfordert, also 0,65 Proc. Verlust. Es ergab sich also, dass unter den oben angegebenen Umständen fast aller Stickstoff in Ammoniak übergeführt war.

\section{Strychnin.}

1. 0,402. Grm., in einer Glasröhre und dem gewöhnlichen Ofen erhitzt, gaben 0,03024 Grm. $\mathrm{H}_{3} \mathrm{~N}=0,0249 \mathrm{Grm} . \mathrm{N}=6,19$ Proc.; nach der Formel: $\mathrm{C}_{42} \mathrm{H}_{22} \mathrm{~N}_{2} \mathrm{O}_{4}$ hätten 8,38 Proc. erhalten werden müssen; also 2,19 Proc. Verlust; offeubar ging also bei diesem Körper die Ammoniakbildung schwerer von Statten. 
2. Die Verbrennung ward desshalb mit $0,308 \mathrm{Grm}$. bei $100^{\circ}$ getrockneter Substanz in dem abgeänderten Ofen nebst Röhre wiederholt; entwickelt $0,02808 \mathrm{Grm} . \mathrm{H}_{3} \mathrm{~N}=0,02312 \mathrm{~N}=7,5 \mathrm{l}$ Proc.; jetzt also nur 0,87 Proc. Verlust. Die höhere Temperatur war also vortheilhaft gewesen.

\section{Morphin.}

$0,495 \mathrm{Grm}$. bei $120^{\circ}$ getrocknet und auf dem gewöhnlichen Wege verbrannt, ergaben: 0,02916 Grm. $\mathrm{H}_{3} \mathrm{~N}=0,02401 \mathrm{Grm} . \mathrm{N}=4,85$ Proc. die Formel $\mathrm{C}_{34} \mathrm{H}_{2} \mathrm{NO}_{6}$ verlangt 4,91 Proc., Verlust $=0,06$ Proc., die Zersetzung hatte vollkommen stattgefunden.

\section{Narcotin.}

Die Untersuchung dieser Base flösste uns grosses Interesse ein wegen der sehr auseinandergehenden Resultate, welche verschiedene Chemiker in Betreff des Stickstoffgehaltes erhalten hatten. Wir fanden *) in dieser Beziehung Folgendes angegeben:

Dumas and Pelletier 7,21. Pelletier 4,31. Liebig 2,51. Regnault 3,46 und 3,52 . Varrentrapp and Will 3,77 and 3,72. Mulder 3,03 and 2,44. Hof fmann 3,30.

Die beiden Extreme weich en also um 4.77 Proc. von einander $a b$, während man dem Narcotin gegenwärtig einen Gehalt von 3,28 Proc. $\mathrm{N}$ zuerkennt in Uebereinstimmung mit der Formel $\mathrm{C}_{46} \mathrm{H}_{25} \mathrm{NO}_{14}$.

Zudem war diess Alkaloïd von Varrentrapp und Will selber nach ihrer Methode untersucht worden. Es ist natürlich, dass mir sofort der Gedanke kam, dass die Stickstoffbestimmung, nach der abgeänderten Methode zur Ausführung gebracht, vielleicht eine grössere Menge Stickstoff in der Form von Ammoniak liefern würde, als von ihnen gefunden worden war, - dass dadurch die grosse Abweichung namentlich von der Analyse von $\mathrm{D}$ u mas und Pelletier könne erklärt werden, und endlich als Folge hiervon, dass man jetzt eine za geringe Menge Stickstoff im Narcotin annehme.

1. $0,64 \mathrm{Grm}$. auf die gewöhnliche Weise verbrannt gaben 0,0243 Grm. $\mathrm{H}_{3} \mathrm{~N}=0,02001 \mathrm{Grm} . \mathrm{N}=3,13$ Proc.

2. 0,613 Grm. in mit Kupferblech umgebener Röhre und abgeändertem Ofen erhitzt, lieferten $0,02052 \mathrm{Grm} . \mathrm{H}_{3} \mathrm{~N}=0,0169 \mathrm{Grm}$. $\mathrm{N}=2,75$ Proc.

*) Gerhardt, Traité de Chimie organique T. IV. p. 64, wo, vermuthlich irrthümlich, als berechueter Stickstoffgehalt 3,31 Proc. verzeichnet ist. 
Meine Vermuthung ward also nicht bestätigt; die gemachten Versuche lehrten, dass die angenommene Formel richtig ist und die höhere Temperatur hier, vermuthlich durch Zersetzung von etwas Ammoniak, nachtheilig wirkt.

Erst nachdem ich obenstehende Analysen gemacht hatte, zog ich die Originalabhandlung von Varrentrapp und Will ${ }^{*}$ ) zu Rathe und erfuhr dadurch zu meinem Erstaunen, dass von den durch uns untersuchten Basen nur $\mathrm{Brucin}$ und $\mathrm{Narcotin}$, die auch uns gute Resultate geliefert hatten, von ihnen analysirt worden waren.

Nirgends fanden wir der Schwierigkeiten Erwähnung gethan, die sich uns bei der Befolgung von Varrentrapp und Will's Methode, namentlich bei den Chinaalkaloiden gezeigt hatten, ausser in einer $\mathrm{Ab}$ handlung von G. J. Mulder "Weber die Dumas'sche Methode der Stickstoffbestimmung“ **), wo wir diese merkwürdigen Worte lesen: „Das Verfahren von Will und Varrentrapp wird von vielen gerühmt und das Resultat vieler Analysen hat bewiesen, dass es für manche recht brauchbar ist. Mir gelang es jedoch nicht so, dass ich mich darauf zu verlassen wagte," und dann einige Zeilen weiter: ,die Menge des Platindoppelsalzes, oder des metallischen Platins zu bestimmen, ist nicht die Schwierigkeit bei dem Verfahren von Will und Varrentrapp, sondern die Verbrennung;" wieder einige Zeilen weiter: „So lange wir kein anderes Verfahren den Stickstoff zu wägen kennen als dieses, scheint mir das Messen noch das beste Resultat zu geben."

Gerne mache ich diese Worte des Utrecht'schen Professors ganz zu den meinigen; die Resultate der von mir gemachten Versuche berechtigen zu keinem andern Ausspruche.

Alles hängt hier von der Temperatur ab, bei der die Behandlung stattfindet und da unsere Versuche gelehrt haben:

1. dass es Körper gibt, deren Stickstoff leicht als Ammoniak entwickelt wird;

2. dass andere zu dem Ende einer höhern Temperatur bedürfen, wobei man zugleich Ammoniakzersetzung zu befürchten hat, was bei geringem Stickstoffgehalt von nachtheiliger.Folge sein kann; und

3. dass wieder andre, wie die Chinabasen, andere flüchtige Basen erzeugen, welche bei einem Wärmegrade zersetzt zu werden scheinen, der von dem, bei welchem sie entstehen, nicht weit entfernt ist,

*) Annal. d. Chem. u. Pharm. Bd. 39. S. $25 \pi$.

**) Scheikundige onderzoekingen Th. IV. S 372. 
so wird der. Schluss gerechtfertigt werden, dass so einfach und ausgezeichnet auch die Methode von Varrentrapp und Will in vielen Fällen sein möge, sie doch nicht unbedingt anempfohlen werden kann, und man sich nie bei ihr allein beruhigen darf, wo es sich um die Stickstoffbestimmung eines uns unbekannten Körpers handelt.

Den auf die Stickstofibestimmung nach der Methode von Varrentrapp and Will bezüglichen Worten E. Mulders*): „Da es besser ist bei einer $z u$ hohen, als bei einer $z u$ niedrigen Temperatur zu arbeiten," dürfen wir also auch nicht in jedem Falle zustimmen, da, auch bei sehr starker Hitze, die Resultate oft sehr abweichend und ungenauer waren, als bei einem niedrigern Wärmegrade.

Wir wiederholen es und schliessen damit, dass das Verfahren zur Stickstoffbestimmung von Varrentrapp und Will, auch nach der Abänderung, nicht s o vortrefflich ist und so wenig zu wünschen übrig lässt, als man vielfach glaubt.

Rot terdam, August 1865 .

\title{
Ueber die quantitative Bestimmung des Kreatins in den Muskeln.
}

\author{
Von \\ Felix Nawrocki aus Warschau **).
}

Im Anschlusse an Professor Heidenhains ***) Untersuchungen über die Beziehung der Arbeit der Muskeln zur Wärmeentwicklung und Stoffumsatz in denselben hat Dr. Basler $\dagger$ ) im vorigen Jahre einige Kreatinbestimmungen gereizter Muskeln im chemischen Labora-

*) Scheikundige verhandelingen en onderzoekingen, Th. III. p. 29.

**) Herr Dr. Naw rocki hat die Güte gehabt die Resultate seiner Untersuchungen über die quantitative Bestimmung des Kreatins in den Muskeln, welche auf Seite 169 dieses Jahrganges in kürzerer (für Mediciner bestimmter) Fassung bereits mitgetheilt worden, in ausführlicher (für Chemiker bestimmter) Darstellung für die Zeitschrift einzusenden. Jene Notiz war dem Centralblatte für die medicinischen Wiss. 1865. N. 27 entnommen und nur der Umstand, dass ein Extraabdruck an die Redaction gelangte, veranlasste die Bemerkung "vom Verfasser mitgetheilt." Der Herausgeber.

***) R. Heidenhain, Mechanische Leistung, WärmeentwickIung und Stoffumsatz bei der Muskelthätigkeit. Leipzig, 1864

†) O. Basler. Quae cum labore musculorum conjunctae sint mutationes chemicae, quaeritur. Vratislaviae 1864. 